\title{
Material properties and compressive local buckling response of high strength steel square and rectangular hollow sections
}

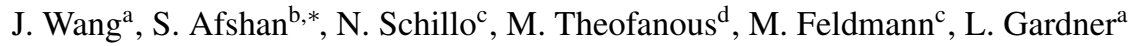 \\ ${ }^{a}$ Imperial College London, London, UK \\ ${ }^{b}$ Brunel University London, London, UK \\ ${ }^{c}$ Institute of Steel Construction, RWTH Aachen University, Germany \\ ${ }^{d}$ University of Birmingham, Birmingham, $U K$
}

\begin{abstract}
An experimental investigation into the structural performance of compressed high strength steel (HSS) square and rectangular hollow sections is described in this paper. Both hot-rolled and cold-formed HSS sections were examined. In total six S460NH and five S690QH hot-rolled section sizes and three S500MC, two S700MC and four S960QC cold-formed section sizes were tested. The experimental programme comprised tensile coupon tests on flat and corner material, measurements of geometric imperfections, full cross-section tensile tests and stub column tests. The results of the experiments presented in this paper have been combined with other available test data on high strength steel sections, and used to assess the existing design guidelines for high strength steels given in Eurocode 3 . The focus has been on the material ductility requirements, the Class 3 slenderness limit for internal elements in compression and the effective width formula for Class 4 internal elements in compression.Reliability assessments of the Class 3 slenderness limit (both the current value of 42 and a proposed value of 38) and the effective width formula for Class 4 internal elements in compression were carried out. The analysis indicated that, based on the assembled test data considered in this study, and the assumptions made regarding the statistical distributions of material and geometric properties, a partial safety factor greater than unity is required for HSS. Similar findings have also recently been presented for ordinary strength steels.
\end{abstract}

\section{Introduction}

High strength steels offer a number of potential advantages over conventional steels, particularly in relation to reduced structural self-weight, as well as savings in the cost of material, transportation and handling. High strength steels have been applied in structural applications in the energy sector e.g. for parts of offshore platforms and in pipelines [1]. Recognising the benefits obtained from their enhanced strength, their use has been extended to building structures, and has grown in recent years [2-4]. With this trend set to increase, the development of codified design rules for high strength steels is imperative. While comprehensive design codes and standards exist for conventional steels, with nominal yield stress typically in the range of $235-355 \mathrm{~N} / \mathrm{mm}^{2}$, for high strength steels, with yield stress in excess of $460 \mathrm{~N} / \mathrm{mm}^{2}$, there is limited guidance available. Therefore, the aim of this paper is to examine the structural behaviour of high strength steel hollow sections from two principal production routes - hot-rolling and cold-forming, and to assess the applicability of existing design guidance. A comprehensive experimental programme, including material tests, stub column tests, full cross-section tensile tests and geometric imperfection measurements has been conducted, the results of which are presented and analysed.

\footnotetext{
${ }^{*}$ Corresponding author

Email address: Sheida.Afshan@brunel.ac.uk (S. Afshan)
} 
The combination of chemical composition, heat treatment and manufacturing processes determine the mechanical properties of steel products. While the strength of steel can be increased by the additions of alloying elements, its other properties, such as ductility, toughness and weldability, can be adversely affected. Heat treatment, which involves cooling at a prescribed rate, refines the material grain size, enabling the manufacture of steels with both higher strength and improved fabrication properties. Hence, heat treatment has been of major importance in the development of new high strength steel grades, and may be used in conjunction with the addition of alloying elements to achieve optimum performance. Cold-working is another means of enhancing the strength of steel materials, and arises during the production of cold-formed structural steel sections. Structural steel products, as covered in EN 1993-1-1 [5] and EN 1993-1-12 [6], may be hot-rolled steels, normalised, quenched and tempered or thermo-mechanically rolled steels.

The conventional hot-rolled steels, with typical rolling finish temperatures of around $750{ }^{\circ} \mathrm{C}$, and with no heat treatment, include the commonly used S235, S275 and S355 grades. Normalised steels, with additions of Carbon (C) and Manganese (Mn), are manufactured through conventional hot-rolling, followed by a normalising heat treatment, whereby the as-rolled material is heated back to and maintained at approximately $900{ }^{\circ} \mathrm{C}$, before being allowed to cool naturally. This process results in a fine and homogeneous grain structure, improving the steel toughness. Similar material properties can also be achieved through a normalised rolling process, whereby the normalising heat treatment is included in the rolling process. The maximum yield stress of normalised steel products is however limited to 460 $\mathrm{N} / \mathrm{mm}^{2}$, beyond which the required steel composition is such that the balance of strength and fabrication properties diminishes [7]. The quenching and tempering process starts with the steel at about $900{ }^{\circ} \mathrm{C}$; the steel is then rapidly cooled, normally in water, and subsequently tempered, where the material is reheated and maintained at about 600 ${ }^{\circ} \mathrm{C}$ before being allowed to cool naturally. Quenching and tempering can be used to produce steel grades with yield strengths up to as high as $1100 \mathrm{~N} / \mathrm{mm}^{2}$ while maintaining reasonable toughness and ductility, although only grades up to $690 \mathrm{~N} / \mathrm{mm}^{2}$ are currently standardised for structural use. Thermo-mechanically rolled steels utilise particular steel compositions, with lower carbon content, that permit lower rolling finish temperatures of about $700{ }^{\circ} \mathrm{C}$. This results in improved weldability and ductility, which cannot generally be achieved by heat treatment alone. The high strength steels examined in this study include, hot-finished normalised and quenched and tempered hollow sections and cold-formed hollow sections from thermo-mechanically rolled sheets and quenched and tempered sheets, hence, allowing comparisons of the structural response of hollow sections from these different production routes to be made.

The material characteristics of high strength steels have been studied in references $[1,8-10]$, where the influence of increasing yield strength on parameters including the ultimate tensile strength to yield strength ratio $f_{u} / f_{y}$, strain at fracture $\varepsilon_{\mathrm{f}}$ and strain at ultimate tensile strength $\varepsilon_{\mathrm{u}}$, were investigated. These three parameters have traditionally been employed in EN 1993-1-1 [5] as measures of the material ductility, and minimum requirements are specified for each before the design rules set out in EN 1993-1-1 may be applied. A similar approach is adopted in EN 1993-1-12 [6], which is the part of Eurocode 3 that provides supplementary rules for high strength steels. In EN 1993-1-12 [6], lower (more relaxed) minimum requirements for the $\mathrm{f}_{\mathrm{u}} / \mathrm{f}_{\mathrm{y}}$ ratio and $\varepsilon_{\mathrm{f}}$ are specified, reflecting the generally lower ductility possessed by high strength steels, but to compensate for the more relaxed ductility requirements, restrictions are placed on certain design aspects (e.g. plastic design is not permitted). A detailed assessment of the applicability of these limits in light of a more comprehensive database of material tests is presented in this paper. In addition, as part of this study, the tensile properties of the examined hot-finished high strength steel hollow sections were measured from full cross-section tensile tests, enabling comparisons with the results of tensile coupon tests to be made. Previous experimental studies on the cross-section behaviour of high strength steel sections, carried out in references [11-13], have focused on the local buckling behaviour of outstand and internal compression plate elements in welded and cold-formed sections. The stub column tests conducted in this study add to the existing database of experimental results, extending its range to hot-finished and cold-formed high strength steel hollow sections from a series of high 
strength steel grades. An analysis of the assembled stub column test results for the assessment of the Class 3 limit for internal elements in compression and the effective width equation for Class 4 internal elements in compression, as given in Eurocode 3, is described in this paper, including a reliability assessment in accordance with Annex D of EN 1990 [14].

\section{Experimental investigation}

\subsection{Introduction}

In this section, an experimental investigation of high strength steel hollow sections, comprising tensile coupon tests, full cross-section tensile tests, measurements of geometric imperfections and stub column tests is described. All tests and measurements were performed in the Structures Laboratory at Imperial College London and RWTH Aachen University. A variety of structural hollow sections including hot-finished S460NH and S690QH and cold-formed S500MC, S700MC and S960QC were examined. Following EN 10210-1 [15] and EN 10149-1 [16], the adopted steel designation system begins with an $\mathrm{S}$ for structural steel, followed by the minimum specified yield strength; the heat treatment is then described using the letters $\mathrm{N}, \mathrm{Q}$ and $\mathrm{M}$ to indicate normalised, quenched and tempered and thermomechanically rolled, which is followed by an $\mathrm{H}$ to designate a hollow section and $\mathrm{C}$ to indicate cold-formed section. The S460NH and S690QH sections were hot-rolled seamlessly from continuously cast round ingots which were then hollowed out in a piercing mill to the final section shape. The S460NH sections were subsequently normalised, while the S690QH sections were quenched and tempered. For both materials, the resulting sections are categorised as hot-finished. The S500MC, S700MC and S960QC sections were cold-formed from hot-rolled coils and welded closed using high frequency induction welding. The coil material was thermo-mechanically rolled for the S500MC and S700MC sections and quenched and tempered for the S960QC sections. A total of six S460NH, five S690QH, three S500MC, two S700MC and four S960QC square and rectangular hollow section sizes, SHS and RHS, respectively, were examined. The chemical compositions and the material properties of the tested specimens, as provided by the mill certificates, are presented in Tables 1 and 2, respectively.

\subsection{Tensile coupon tests}

The basic stress-strain properties of the investigated high strength steel hollow sections were obtained from tensile coupon tests on the flat and corner material. For the hot-finished S460NH and S690QH sections, four parallel flat coupons were machined from each of the four faces of the grade S460NH SHS $50 \times 50 \times 5$ and SHS $100 \times 50 \times 6.3$ and grade S690QH SHS $50 \times 50 \times 5$ and SHS $100 \times 50 \times 6.3$ specimens (labelled F1-F4 in Figure 1a). For the remaining hot-finished sections, only two parallel flat coupons (labelled F1 and F2 in Figure 1a) were machined. For the cold-formed S500MC, S700MC and S960QC sections, four parallel flat coupons, extracted from each of the four faces of the sections, (labelled F1-F4 in Figure 1b) were tested. Three corner coupons (labelled C1-C3 in Figure 1b) were also extracted and tested for each of the cold-formed sections to examine the influence of the high localised plastic strains in the corner regions. For the hot-finished sections, one corner coupon (labelled C in Figure 1a) was tested to confirm the uniformity of properties around the sections. All tensile flat and corner coupons were cut out in the longitudinal (rolling) direction, and dimensioned in accordance with EN ISO 6892-1 [17].

All tests were performed in an Instron $600 \mathrm{kN}$ hydraulic testing machine in line with the procedures set out in EN ISO 6892-1 [17]. Strain control was used to drive the testing machine at a strain rate of $0.007 \% / s$ up to the yield stress and then $0.025 \% / s$ until fracture. A gradual transition in the strain rate was adopted between these points to avoid a sudden jump in the measured stress-strain curves. Linear electrical resistance strain gauges, affixed at the midpoint of each side 
of the tensile coupons, and a clip-on extensometer, mounted directly on the coupons with a gauge length of $100 \mathrm{~mm}$, were used to measure the strain for the hot-finished S460NH and S690QH specimens. For the cold-formed specimens, an optical extensometer, with gauge lengths of $60 \mathrm{~mm}$ and $80 \mathrm{~mm}$ for the S500MC/S700MC and S960QC coupons, respectively, was used to measure the strain. All data, including load, displacement, strain and other relevant variables were recorded at one second intervals using the DATASCAN data acquisition system. Typical measured stress-strain curves from the S460NH, S690QH, S500MC, S700MC and S960QC high strength steel material are shown in Figure 2. A summary of the average material properties obtained from the tensile flat and corner coupon tests for each section size are reported in Tables 3 and 4, respectively. The parameters reported in Tables 3 and 4 are the material yield strength $f_{y}$, taken as the upper yield strength for the hot-finished sections $[5,17]$ and the $0.2 \%$ proof stress for the cold-formed sections [5], the ultimate tensile strength $\mathrm{f}_{\mathrm{u}}$, the strain at the ultimate tensile strength $\varepsilon_{\mathrm{u}}$, the plastic strain at fracture $\varepsilon_{\mathrm{f}}$ (based on an original standard gauge length of $\mathrm{L}_{\mathrm{o}}=5.65 \sqrt{\mathrm{A}_{\mathrm{c}}}$, where $\mathrm{A}_{\mathrm{c}}$ is the cross-section area of the coupon), the cross-sectional area reduction at fracture $\mathrm{Z}$ and the tensile to yield strength ratio $\mathrm{f}_{\mathrm{u}} / \mathrm{f}_{\mathrm{y}}$. It should be noted that the reported plastic strains at fracture $\varepsilon_{\mathrm{f}}$ for the S500MC and S700MC coupons in Table 3 are based on a gauge length of $60 \mathrm{~mm}$, which will give slightly lower (i.e. conservative) calculated fracture strains than would have been obtained from the shorter standard gauge length of $40 \mathrm{~mm}$. The addition of a subscript $\mathrm{c}$ to the above notation indicates corner material.

The characteristics of the stress-strain curves of the tested high strength steels, as illustrated in Figure 2, may be directly related to their manufacturing processes. While the hot-finished S460NH and S690QH materials display the anticipated sharply defined yield point, yield plateau and strain hardening, the cold-formed S500MC, S700MC and S960QC materials exhibit a rounded stress-strain behaviour with no sharply defined yield point. Also, as expected, the measured material properties of the flat and corner coupons extracted from the hot-finished sections are similar to their respective mill certificate properties, since the same material is essentially being tested. The mill certificate properties of the cold-formed sections reported in Table 2, which are based on coupon tests on the flat faces of the formed sections carried out by the manufacturer, are also similar to those obtained from the flat coupon tests conducted herein. The plastic deformations experienced during the cold-forming of the S500MC, S700MC and S960QC sections result in an increase in the material yield stress and a reduction in ductility; these effects are clearly evident from the results of tests on corner coupons, which have undergone high degrees of plastic strains. Similar observations have been made for the case of ordinary structural steel and stainless steel cold-formed sections as investigated in [18]. For the hot-finished sections, the flat and corner coupons behave similarly, but the corner coupons exhibit slightly lower ductility; this may be due to the manner in which the corner coupons were gripped since these coupons typically fractured near the jaws of the tensile testing machine. Alternative gripping techniques for curved coupons, such as clamping the coupons in pairs around a circular bar [18] at the ends and loading the coupon through pins [19, 20], have been adopted in previous studies to attempt to overcome such problems. Ratios of the corner to flat yield strength $f_{y c} / f_{y}$, ultimate tensile strength

$\mathrm{f}_{\mathrm{uc}} / \mathrm{f}_{\mathrm{u}}$, strain at ultimate tensile strength $\varepsilon_{\mathrm{uc}} / \varepsilon_{\mathrm{u}}$, plastic strain at fracture $\varepsilon_{\mathrm{fc}} / \varepsilon_{\mathrm{f}}$, area reduction $\mathrm{Z}_{\mathrm{c}} / \mathrm{Z}$, and $\frac{\mathrm{f}_{\mathrm{uc}}}{\mathrm{f}_{\mathrm{yc}}} / \frac{\mathrm{f}_{\mathrm{u}}}{\mathrm{f}_{\mathrm{y}}}$ are reported in Table 5.

\subsection{Full cross-section tensile tests}

While tensile coupon tests provide a measure of the local engineering stress-strain response of structural sections, a full insight into the tensile performance of the whole cross-section, allowing for the influence of the distribution of material properties and residual stresses, may be obtained from full cross-section tensile tests. Of particular interest was the length of the yield plateau, rather than the average strength enhancement due to cold-worked corners which has been examined previously [18], and hence testing was focussed on the hot-finished sections. In this study, one full cross-section tensile test was performed on each of the S460NH and S690QH high strength steel hollow sections. 
Accurate measurements of the geometric dimensions of the tested specimens were made before testing and are reported in Table 6, where $\mathrm{L}$ is the length of the specimen between the two end plates, as depicted in Figure $3 \mathrm{~b}, \mathrm{~h}$ is the depth of the section, $b$ is the breadth of the section, $t$ is the thickness of the section and $r_{i}$ is the inner corner radius, as illustrated in Figure 1a.

The general test set-up configuration is depicted in Figure 3a. Two $20 \mathrm{~mm}$ thickness end plates were welded onto the ends of each of the specimens with four vertical triangular stiffeners of $60 \mathrm{~mm}$ leg length (See Figure 3b) added to increase the weld length and to ensure uniform loading distribution during testing. All tests were carried out in an Instron $2000 \mathrm{kN}$ hydraulic testing machine in accordance with the procedures set out in EN ISO 6892-1:2009 [17]. The end plates of the specimen were securely bolted to the end platens of the testing machine prior to testing. Displacement control, with rates of $0.4 \mathrm{~mm} / \mathrm{min}$ up to a displacement of $0.8 \mathrm{~mm}, 1.0 \mathrm{~mm} / \mathrm{min}$ between 0.8 to $1.8 \mathrm{~mm}$ displacement and $3.0 \mathrm{~mm} / \mathrm{min}$ until fracture, was used to drive the testing machine. Tensile strain was measured using a combination of eight LVDTs distributed at uniform locations on the top and bottom end plates and strain gauges attached to the four faces of the section at mid-height. The corrected LVDT data, adjusted with reference to the strain gauge readings to eliminate the elastic deformation of the end plates and the influence of the stiffeners, were used to plot the full stress-strain responses of the specimens. Table 7 presents the key results of the full cross-section tensile tests; all symbols are as previously defined for the tensile coupon tests, but with subscript cs to denote cross-section tests. Note that the plastic strain at fracture was measured over the total length of the specimen L. Typical failure modes of the tested specimens are shown in Figure 4. The grade S690QH SHS $90 \times 90 \times 5.6$ and SHS $100 \times 100 \times 5.6$ specimens failed by fracture near the specimen ends as depicted in Figure 4a, while for all other specimens, fracture occurred at or near the mid-height of the specimens as shown in Figure $4 \mathrm{~b}$.

\subsection{Geometric imperfection measurements}

Measurements of local geometric imperfections were conducted for all the twenty investigated high strength steel hollow section sizes. The experimental set-up employed in this study for the imperfection measurements on the S460NH and S690QH sections was similar to that used by Schafer and Peköz [21]; representative $1700 \mathrm{~mm}$ long samples of each of the twenty section sizes were mounted on the bed of a milling machine, where the flat surface provided a reference plane, relative to which the vertical fluctuations of the faces of the sections of the central 900 $\mathrm{mm}$ (to avoid influences from cutting and the release of residual stress at the member ends) were measured. A linear variable differential transformer (LVDT) fitted on the head of the milling machine was moved along the specified 900 $\mathrm{mm}$ length on each of the four faces of the section at three positions - at the centreline of each face and at near the two edges of each face, resulting in a total of twelve runs per section. The maximum difference between the centreline and the average of the two edge runs was taken as the local imperfection amplitude for each face of the section. For the case of S500MC, S700MC and S960QC specimens, a laser transducer was used to record the local geometric imperfections of the stub column specimens at five measurement positions across each of the faces of the sections. This enabled a 3D-plot of the profiles of each of the faces of the sections to be created, which was thereafter approximated with a best fit surface, assuming a three-half-wave shape in the longitudinal direction and a single half-wave shape in the transverse direction, as illustrated in Figure 5.

The geometric imperfection amplitude for each cross-section, taken as the maximum value from the four faces, are reported in Table 8 and denoted $\omega_{0}$. The EN 10210-2 [15] and EN 10219-2 [22] maximum out-of-flatness tolerances for hot-finished and cold-formed tubular sections, specified as $1.0 \% \mathrm{~b}$ and $0.8 \% \mathrm{~b}$, respectively, are also presented in Table 8 , denoted $\omega_{\mathrm{EN}}$. Figures $6 \mathrm{a}$ and $6 \mathrm{~b}$ show the variation of $\omega_{0}$ and the $\omega_{0} / \omega_{\mathrm{EN}}$ with the cross-section slenderness $\bar{\lambda}_{\mathrm{p}}$, defined in accordance with EN 1993-1-5 [23] and taken as that of the most slender constituent plate element in the 
cross-section. As shown in Figure 6a, the imperfections generally increase with plate slenderness, and are higher for the cold-formed sections than the hot-finished sections (by approximately seven times on average). Figure $6 \mathrm{~b}$ shows that the measured out-of-straightness was generally within the specified tolerances, except for one of the S960 sections, where the imperfections marginally exceeded these limit by about $15 \%$.

\subsection{Stub column tests}

A total of twenty nine stub columns were tested under pure axial compression - one test for each of the hot-finished S460NH and S690QH sections and two repeated tests for each of the cold-formed S500MC, S700MC and S960QC sections, denoted (1) and (2) in Table 9. The selected stub column lengths conformed to the requirements in [24], which ensured that the specimens were short enough to avoid overall buckling, but still included a representative distribution of geometric imperfections and residual stresses. The measured geometric dimensions of the stub column specimens are presented in Table 9, where $\mathrm{L}$ is the stub column length and all other symbols are as previously defined in Figure 1. Residual stress measurements on hot-finished sections were made in a previous study [25] and found to be of low magnitude, up to $6 \%$ of the yield strength in tension and 3\% in compression. The compression tests were carried out in an Instron $3500 \mathrm{kN}$ hydraulic testing machine for the hot-finished S460NH and S690QH specimens and in a Zwick/Roell $5000 \mathrm{kN}$ hydraulic testing machine for the cold-formed S500MC, 700MH and 960QH specimens. The tests were displacement controlled, with displacement rates of $0.2 \mathrm{~mm} / \mathrm{min}$ for the hot-finished S460 SHS $50 \times 50 \times 5$ and $50 \times 50 \times 4$ and S690 $50 \times 50 \times 5$ specimens, $0.3 \mathrm{~mm} / \mathrm{min}$ for the remaining hot-finished sections and $1 \mathrm{~mm} / \mathrm{min}$ for the cold-formed specimens. The stub column specimens were compressed between the two parallel end platens of the testing machines and the average end-shortening was measured using three linear variable displacement transformers (LVDTs). Four linear electrical resistance strain gauges were affixed to each specimen at mid-height. The strain gauges were positioned at the centreline of each face of the cross-sections. The strain gauge readings were used to remove the elastic deformation of the end platens from the LVDT end shortening measurements in accordance with the guidelines provided by the Centre for Advanced Structural Engineering [26].

The normalised load-end shortening curves - N/Af versus $\delta / \mathrm{L}$, for all stub columns investigated in this study are depicted in Figure 7, where $\mathrm{N}$ is the measured load, $\mathrm{A}$ is the gross cross-sectional area, $\mathrm{f}_{\mathrm{y}}$ is the measured tensile yield strength, $\delta$ is the measured end-shortening and $\mathrm{L}$ is the length of the specimen. The yield strength $\mathrm{f}_{\mathrm{y}}$ was taken as the average of the flat faces for the hot-finished sections and the weighted average value, allowing for the strength enhancements of the corner regions, for the cold-formed sections. The recorded ultimate load $N_{u}$ and the corresponding end shortening at ultimate load $\delta_{\mathrm{u}}$ are reported in Table 10. The observed failure modes included local buckling, elephant-foot buckling and global buckling triggered by initial local buckling, as shown in Figure 8 . While the load end-shortening curves display a distinct yield point for the hot-finished specimens, the response of the cold-formed sections is more rounded. As expected, the stocky hot-finished sections exhibit superior normalised load carrying capacity $\mathrm{N}_{\mathrm{u}} /$ Afy and normalised deformation capacity $\delta_{\mathrm{u}} / \mathrm{L}$ compared to the more slender cold-formed sections, which failed by local buckling prior to reaching the cross-section yield load.

\section{Analysis of results and discussion}

In this section, the results of the experiments described above, supplemented with those collected from the literature, have been used to assess the current high strength steel design guidelines set out in EN 1993-1-12 [6] with a focus on 1) the material ductility requirements, 2) the Class 3 cross-section classification limit for internal elements in compression and 3) the effective width equation for Class 4 internal elements in compression. The overall response of the high strength steel hollow sections from the full cross-section tensile tests is also compared with that obtained from the 
tensile coupons tests.

\subsection{Assessments of material ductility requirements}

Material ductility is of paramount importance in the design of steel structures, and is implicitly relied upon in a number of scenarios, such as in plastic design and in the design of connections, where significant inelastic deformation and the redistribution of forces is assumed. For steel structures designed to Eurocode 3, a series of ductility requirements are set out.

For material grades up to and including S460, the ductility requirements given in EN 1993-1-1 [5] are:

- $\mathrm{f}_{\mathrm{u}} / \mathrm{f}_{\mathrm{y}} \geq 1.10$

- $\varepsilon_{\mathrm{f}} \geq 15 \%$

- $\varepsilon_{\mathrm{u}} / \varepsilon_{\mathrm{y}} \geq 15$

For higher strength steels, up to S700, the following, more relaxed ductility requirements are set out in EN 1993-1-12 [6]:

$$
\begin{aligned}
& \text { - } \mathrm{f}_{\mathrm{u}} / \mathrm{f}_{\mathrm{y}} \geq 1.05 \\
& \text { - } \varepsilon_{\mathrm{f}} \geq 10 \% \\
& \text { - } \varepsilon_{\mathrm{u}} / \varepsilon_{\mathrm{y}} \geq 15
\end{aligned}
$$

However, the restriction associated with adopting these more relaxed limits is that the use of plastic analysis and the design rules for semi-rigid joints is not allowed for these higher strength steels, though exploiting the plastic resistance at cross-section level is still permitted for Class 1 and Class 2 sections.

In Figure 9, the results from the tensile coupon tests carried out in the present study on both the flat $(\mathrm{F})$ and corner (C) material have been combined with those collated from the literature, reported in references [11-13, 27-36], and used to assess the variation of the $f_{u} / f_{y}$ ratio with yield stress $f_{y}$. The observed trend of decreasing values of $f_{u} / f_{y}$ with increasing yield stress $f_{y}$ is in line with previous findings $[8,10,37]$, and reflects the fact that strengthening mechanisms used in the production of high strength steels bring about significant increases in the yield strength, but have less influence on the ultimate tensile strength [1]. Empirical relationships to describe the variation of $f_{u} / f_{y}$ with yield strength have been proposed by Fukumoto [9] and Langenberg [10], as given by Eqs. (1) and (2) respectively; these expressions are also depicted in Figure 9 for comparison purposes. Both expressions may be seen to offer a reasonable representation of the collected results. Examination of the test data presented in Figure 9 shows that steels with yield strength between $460 \mathrm{~N} / \mathrm{mm}^{2}$ to $700 \mathrm{~N} / \mathrm{mm}^{2}$ can meet the EN 1993-1-12 requirement of $\mathrm{f}_{\mathrm{u}} / \mathrm{f}_{\mathrm{y}}>1.05$, and in fact the stricter limit of 1.10 is also generally satisfied within this strength range.

$$
\begin{gathered}
\mathrm{f}_{\mathrm{u}} / \mathrm{f}_{\mathrm{y}}=0.83+203.8 / \mathrm{f}_{\mathrm{y}} \\
\mathrm{f}_{\mathrm{u}} / \mathrm{f}_{\mathrm{y}}=\left[1-0.72 \mathrm{e}^{\left(-0.0027 \mathrm{f}_{\mathrm{y}}\right)}\right]^{-1}
\end{gathered}
$$

The ductility requirement based on strain at fracture $\varepsilon_{\mathrm{f}}$ for high strength steels is examined in Figure 10, where the measured strain at fracture from the tensile coupon tests conducted herein and those collected from the literature, given 
in references [27-32, 35], is plotted against the yield strength $\mathrm{f}_{\mathrm{y}}$. As anticipated, a general decreasing trend of $\varepsilon_{\mathrm{f}}$ with $\mathrm{f}_{\mathrm{y}}$ exists. Within the strength range of $460 \mathrm{~N} / \mathrm{mm}^{2}$ to $700 \mathrm{~N} / \mathrm{mm}^{2}$, both the EN 1993-1-1 and EN 1993-1-12 minimum specified strain at fracture ductility limits, equal to $15 \%$ and $10 \%$, respectively, are met by the material from both the hot-finished and cold-formed high strength steel sections, with the exception of a few results from the corner coupons of the cold-formed sections, which fall below the $15 \%$ limit but still exceed the $10 \%$ value. High strength steels beyond the current scope of EN 1993-1-12 (i.e. those with $\mathrm{f}_{\mathrm{y}}>700 \mathrm{~N} / \mathrm{mm}^{2}$ ), generally show lower strains at fracture $\varepsilon_{\mathrm{f}}$, but the majority of the test data still satisfy the 10\% limit, indicating the possibility of extending the scope of EN 1993-1-12 to higher steel grades. Given the dependency of fracture strain on the adopted gauge length, discussions on the use of percentage area reduction at fracture $\mathrm{Z}$ as a measure of ductility in place of the $\varepsilon_{\mathrm{f}}$ parameter are presented in [10, 38]; values of percentage area reduction at fracture $\mathrm{Z}$ for the tensile coupon tests performed in this study are presented in Tables 3 and 4 .

The ratios of ultimate-to-yield strain $\varepsilon_{\mathrm{u}} / \varepsilon_{\mathrm{y}}$ obtained from the tests are plotted against the yield strength in Figure 11, along with the minimum requirement set out in EN 1993-1-1 and EN 1993-1-12 of $\varepsilon_{\mathrm{u}} / \varepsilon_{\mathrm{y}}=15$. In general, the hot-finished material displays higher $\varepsilon_{\mathrm{u}} / \varepsilon_{\mathrm{y}}$ values than the cold-formed material, but the limit $\varepsilon_{\mathrm{u}} / \varepsilon_{\mathrm{y}}=15$ may be seen to provide a lower bound to all the test data that fall within the scope EN 1993-1-12, i.e. $460<\mathrm{f}_{\mathrm{y}}<700$, apart from a few corner coupons of the cold-formed sections. For higher yield strengths, up to about $800 \mathrm{~N} / \mathrm{mm}^{2}$, the $\varepsilon_{\mathrm{u}} / \varepsilon_{\mathrm{y}}=15$ limit was met by some test results, but not others, while for $\mathrm{f}_{\mathrm{y}} \geq 800 \mathrm{~N} / \mathrm{mm}^{2}$, all test data failed to satisfy this requirement.

It should be noted that, although the Eurocode 3 limits on the $\mathrm{f}_{\mathrm{u}} / \mathrm{f}_{\mathrm{y}}$ ratio, elongation at fracture $\varepsilon_{\mathrm{f}}$ and ultimate to yield strain ratio $\varepsilon_{\mathrm{u}} / \varepsilon_{\mathrm{y}}$ have been shown to be generally satisfied by the considered high strength steel test data, the basis for these limits, particularly the more relaxed values given in EN 1993-1-12 remains unclear, and worthy of further investigation [39]. Furthermore, although these three parameters have traditionally been employed as a measure of material ductility, minimum ductility requirements based on a damage mechanics framework may be more appropriate, as discussed in [10, 34, 40-43].

\subsection{Comparisons of full cross-section tensile tests and tensile coupon tests}

The material properties of structural steel sections are usually obtained by performing tensile coupon tests. The obtained stress-strain response is therefore dependent on the location in the section from which the coupon was cut, and the influence of differential cooling rates in hot-finished sections and induced plastic strains in cold-formed sections may not be fully captured. In order to assess the extent to which the results of tensile coupon tests differ from the overall tensile behaviour of hot-finished high strength steel hollow cross-sections, the results from tensile coupon tests, presented in Section 3.2, and those from the full cross-section tensile tests, presented in Section 3.3, are compared herein. Figures 12a and $12 \mathrm{~b}$ display the measured stress-strain curves from both the tensile flat coupon tests and the full cross-section tensile tests for the S460NH and S690QH RHS $100 \times 50 \times 6.3$ specimens, respectively. The stress-strain curves from both test types are similar in that both consist of a sharply defined yield point, followed by a yield plateau and then strain hardening. A reduction in the length of the yield plateau is observed for the case of full cross-section tensile tests compared with their respective tensile coupon test results. The average yield plateau for the coupons is $\varepsilon=1.96 \%$, whilst for the full cross-section tensile tests the average yield plateau is $\varepsilon=1.55 \%$. Ratios of yield strength $\mathrm{f}_{\mathrm{y}}$, ultimate tensile strength $\mathrm{f}_{\mathrm{u}}$, strain at fracture $\varepsilon_{\mathrm{f}}$ and $\mathrm{f}_{\mathrm{u}} / \mathrm{f}_{\mathrm{y}}$ from the full cross-section tensile tests, denoted by subscript (cs), and the tensile flat coupon tests are reported in Table 11. The ratio of yield stress $\mathrm{f}_{\mathrm{y}, \mathrm{cs}} / \mathrm{f}_{\mathrm{y}}$ lies within the range of 0.95 to 1.07 , while that for the ultimate tensile strength $f_{u, c s} / f_{u}$ is between 0.96 and 1.16 , indicating a relatively small difference between these testing methods for the examined hot-finished high strength steel 
hollow sections. More significant differences have been found in sections of variable thickness, such as UBs and UCs [44]. The lower fracture strain displayed by the full cross-section tensile tests relates to the gauge length over which it was measured, which was taken as the full length of the specimen, since no standard gauge lengths exist for full cross-sections, hence making the comparisons with the respective coupon test results of limited validity.

\subsection{Assessment of Eurocode Class 3 slenderness limits for internal elements in compression}

Whether in the elastic or inelastic material range, the cross-section resistance and rotation capacity of structural steel sections are limited by the effects of local buckling. Eurocode 3 accounts for the effects of local buckling through the cross-section classification method, whereby cross-sections are placed into four behavioural classes depending upon the material yield stress $f_{y}$, width-to-thickness ratios $c / t$ of the individual compression elements within the cross-section and the stress distribution arising from the applied loading. The limiting width-to-thickness ratios against which cross-sections are classified are given in EN 1993-1-1 [5] for ordinary carbon steels; these have also been adopted in EN 1993-1-12 [6] for high strength steels. Cross-sections that are capable of reaching their yield load Af are classified as Class 1,2 or 3 and are considered to be fully effective in compression, while those which fail due to local buckling prior to attaining $\mathrm{Af}_{\mathrm{y}}$ are Class 4 . Test data on high strength steel stub columns have been collected and carefully analysed in this section to assess the suitability of the Class 3 [5] limit for internal elements in compression.

Figure 13 compares the EN 1993-1-1 Class 3 limit for internal elements in compression (c/t $\varepsilon=42)$ with the results of stub column test on high strength steels from this study and those collected from the literature [11-13, 45-52]. Stub column test data on lower steel grades, with nominal yield strength between $260 \mathrm{~N} / \mathrm{mm}^{2}$ and $450 \mathrm{~N} / \mathrm{mm}^{2}$, from $[13,49,53-56]$ have also been presented in Figure 13 for comparison purposes. In Figure 13, the ultimate load $\mathrm{N}_{\mathrm{u}}$ reached in the tests has been normalised by the cross-section yield load, taken as the product of the cross-sectional area A and yield strength $\mathrm{f}_{\mathrm{y}}$, and plotted against the local slenderness parameter $\mathrm{c} / \mathrm{t} \varepsilon$, where $\mathrm{c}$ is the flat element width, $\mathrm{t}$ is the plate thickness and $\varepsilon$ is the EN 1993-1-1 material parameter. The yield strength $\mathrm{f}_{\mathrm{y}}$ was taken as the average of those of the flat faces (Table 3) for the hot-finished sections and the area weighted average value, allowing for the higher strength material in the corners, for the cold-formed sections.

In determining the $\mathrm{c} / \mathrm{t} \varepsilon$ parameter, due account of the element interaction effect, whereby the less slender elements in the cross-section provide restraint to the more slender ones [57], present in the case of rectangular hollow sections, has been made, as explained hereafter. The cross-section elastic buckling stress, $\sigma_{\mathrm{cr}, \mathrm{cs}}$, allowing for element interaction, was determined by means of the CUFSM software [58]. This was then used to define an equivalent plate width by rearranging the equation for the elastic buckling stress, $\sigma_{\mathrm{cr}}$, given in Eq. (3), where $\mathrm{t}$ and $\mathrm{b}$ are the plate thickness and width, respectively, $\mathrm{E}$ is the Young's modulus (taken as those reported in Table 3), $\nu$ is the Poisson's ratio (taken as 0.3) and $\mathrm{k}_{\sigma}$ is the plate buckling coefficient. Taking $\sigma_{\mathrm{cr}}$ equal to $\sigma_{\mathrm{cr}, \mathrm{cs}}$, from CUFSM [58], based on centreline dimensions and round corners, and setting $\mathrm{k}_{\sigma}=4.0$, which is the buckling coefficient for an internal element in compression [23], the equivalent width $\mathrm{b}_{\text {eq,cl }}$ is obtained - see Eq. (4). This equivalent width relates to the cross-section centreline geometry, and has been multiplied by the web flat width $b_{\text {flat }}$ to centreline width $b_{c l}$ ratio $b_{f l a t} / b_{c l}$ to give the equivalent flat width $b_{\text {eq,flat }}$ to maintain consistency with the EN 1993-1-1 definition of flat width in the $c / t \varepsilon$ slenderness parameter, as given in Eq. (5). For the rolled and welded square hollow sections, where no element interaction effect exists, $c$ is simply taken as the flat element width $b_{\text {flat }}$ in line with the EN 1993-1-1 [5] definitions.

$$
\sigma_{\mathrm{cr}}=\frac{\mathrm{k}_{\sigma} \pi^{2} \mathrm{E}}{12\left(1-\nu^{2}\right)}\left(\frac{\mathrm{t}}{\mathrm{b}}\right)^{2}
$$




$$
\begin{gathered}
\mathrm{b}_{\text {eq }, \mathrm{cl}}=\sqrt{\frac{\mathrm{k}_{\sigma} \pi^{2} \mathrm{Et}^{2}}{12\left(1-\nu^{2}\right)} \times \frac{1}{\sigma_{\mathrm{cr}, \mathrm{cs}}}} \\
\mathrm{c}=\mathrm{b}_{\text {eq,flat }}=\mathrm{b}_{\text {eq }, \mathrm{cl}} \times \frac{\mathrm{b}_{\text {flat }}}{\mathrm{b}_{\mathrm{cl}}}
\end{gathered}
$$

From Figure 13, it can be seen that the current Eurocode Class 3 limit for internal elements in compression, c/t $\varepsilon=42$, appears optimistic for both high strength steel and ordinary carbon steel sections, with the mean trend of the data passing through unity on the vertical axis at a lower $\mathrm{c} / \mathrm{t} \varepsilon$ value. This limit is also incompatible [59] with the $\bar{\lambda}_{\mathrm{p}}=0.673$ slenderness limit which marks the transition from non-slender Class 3 to slender Class 4 internal compression elements, as defined in EN 1993-1-5 [23]. The limiting $\mathrm{c} / \mathrm{t} \varepsilon$ ratio corresponding to the $\bar{\lambda}_{\mathrm{p}}=0.673$ slenderness limit is 38 ; it is this value which has been proposed in [60] to be adopted as the new Class 3 limit for internal elements in compression for the design of ordinary carbon steel sections. This new slenderness limit $\mathrm{c} / \mathrm{t} \varepsilon=38$ is also depicted in Figure 13 to assess its suitability for the case of high strength steels. The reliability of both these limits when used to predict the compression capacity of high strength steel hollow sections is assessed in Section 3.5.

\subsection{Assessment of Eurocode effective width equation for internal elements in compression}

Within the Eurocode 3 cross-section classification framework, the reduction in the compressive resistance of Class 4 sections due to local instabilities is accounted for through the traditional effective width method. The method identifies and excludes areas of the cross-section that are deemed ineffective due to local buckling, and bases subsequent calculations on the remaining effective area $\mathrm{A}_{\text {eff. }}$. The effective area of a flat compression element is defined in Clause 4.4 of EN 1993-1-5 [23] as its gross cross-sectional area multiplied by a reduction factor $\rho$, which is a function of its local slenderness $\bar{\lambda}_{\mathrm{p}}$. The reduction factor $\rho$ for an internal element in compression, e.g. the plate elements in RHS and SHS, is given by Eq. (6), where $\bar{\lambda}_{\mathrm{p}}$ is the plate slenderness and is obtained as the square root of the ratio of the yield stress $\mathrm{f}_{\mathrm{y}}$ to the plate elastic buckling stress $\sigma_{\mathrm{cr}}$. Based on the same collection of test data presented in Figure 13, the effective width equation for slender Class 4 internal elements in compression, presented in Eq. (6), is examined in this section. In Figure 14, the ultimate load reached in the tests, normalised in the same manner as explained in Section 3.3, has been plotted against the cross-section slenderness $\bar{\lambda}_{\mathrm{p}}$, obtained from the CUFSM software [58] for the RHS and taken as the plate slenderness (due to the absence of element interaction effects), based on the flat element width of $\left(b-2 t-2 r_{i}\right)$, for the SHS specimens. From Figure 14, it is evident that the codified effective width equation for internal elements in compression lies above the majority of the test data for both high strength steel and ordinary carbon steel sections, as has also been observed in [12, 48], leading to unsafe predictions of the cross-section compressive resistance. Statistical reliability analysis to determine the partial safety factor required for use in conjunction with the EN 1993-1-5 effective width equation is performed and discussed in Section 3.5.

$$
\rho=\frac{1}{\bar{\lambda}_{\mathrm{p}}}-\frac{0.22}{\bar{\lambda}_{\mathrm{p}}^{2}} \quad \text { but } \rho \leq 1.0 \quad \text { for } \quad \bar{\lambda}_{\mathrm{p}} \geq 0.673
$$

\subsection{Reliability analysis}

Reliability assessments of the above discussed Class 3 limits for internal elements in compression (c/t $\varepsilon$ equal to 42 and 38) and the EN 1993-1-5 [23] effective width equation for Class 4 internal elements in compression are carried out in this section. The statistical procedures set out in Annex D of EN 1990 [14] are applied to the stub column test results presented in Sections 3.3 and 3.4 to determine the required partial safety factors. Based on material data collected from steel producers, representative values of the mean to nominal yield stress ratio, i.e. the material over-strength, $\mathrm{f}_{\mathrm{y}, \text { mean }} / \mathrm{f}_{\mathrm{y} \text {, nom }}$ and coefficient of variation (COV) of material yield stress, $V_{\mathrm{f}_{\mathrm{y}}}$ equal to 1.135 and 0.055 , respectively were adopted. These values were used for all the high strength steel grades considered in this study, since no significant variation in the values of these parameters were observed for the studied grades. In their study of high strength steel 
welded box sections, Schillo et al. [61] adopted different over-strength and COV values for the yield strength of different high strength steel grades. The coefficient of variation of the geometric properties was taken as 0.02 , which has also been adopted in similar studies in [62] and [63].

\subsubsection{Class 3 slenderness limit}

The compression resistance of a Class 1, 2 or 3 cross-section $\mathrm{N}_{\mathrm{c}, \mathrm{Rd}}$, as set out in Clause 6.2.4 of EN 1993-1-1, is determined from Eq. (7), where $f_{y}$ is the material yield stress, $A$ is the cross-sectional area and $\gamma_{\mathrm{M} 0}$ is the partial safety factor. This resistance function may be more generally expressed as given in Eq. (8), where $\alpha_{\mathrm{c}, \mathrm{Rd}}$ provides a linear relationship between the predicted compression resistance $\mathrm{N}_{\mathrm{c}, \mathrm{Rd}}$ and the cross-section slenderness parameter $\mathrm{c} / \mathrm{t} \varepsilon$. In the reliability analyses performed herein, the cross-section compression resistance has been evaluated from Eq. (8), referred to as the theoretical resistance function $r_{t}$.

In Figure 15, the cross-section ultimate compression resistances, normalised as explained in Section 3.3, is plotted against the slenderness parameter $\mathrm{c} / \mathrm{t} \varepsilon$, obtained as described in Section 3.3. Fitting a linear regression line through these data, the expression for $\alpha_{\mathrm{c}, \mathrm{Rd}}$ is obtained. The EN 1990 Annex D method was applied to the theoretical resistance function $r_{t}$, presented in Eq. (8), to determine its corresponding design resistance function $r_{d}$, obtained from Eq. (9), where $b$ is the mean value correction factor, $r_{t}$ is the theoretical resistance function evaluated for the mean (measured) values of the basic variables, $\mathrm{k}_{\mathrm{d}, \mathrm{n}}$ is the design fractile factor for $\mathrm{n}$ data points, $\mathrm{k}_{\mathrm{d}, \infty}$ is the design fractile factor for $\mathrm{n}$ tending to infinity and $\mathrm{Q}_{\mathrm{rt}}, \mathrm{Q}_{\delta}, \alpha_{\mathrm{rt}}, \alpha_{\delta}$ and $\mathrm{Q}$ are the reliability analysis parameters as defined in Annex D of EN 1990. The effect of the over-strength ratio on the partial safety factor $\gamma_{\mathrm{M} 0}$ has been allowed for by factoring up the design resistance equation by the $f_{y, \text { mean }} / f_{y, n o m}$ ratio. The required partial safety factor $\gamma_{M 0}=r_{n} / r_{d}$ for the two Class 3 slenderness limits (42 and 38) were therefore defined as the ratio of the nominal resistance, from the Eurocode 3 resistance model, to the design resistance $\left(\mathrm{r}_{\mathrm{d}} \times \mathrm{f}_{\mathrm{y}, \text { mean }} / \mathrm{f}_{\mathrm{y}, \mathrm{nom}}\right)$, as illustrated in Figures 15 . Table 12 provides a summary of the key statistical parameters obtained, where $\mathrm{V}_{\delta}$ is the coefficient of variation of the test results relative to the resistance model, $V_{\mathrm{r}}$ is the combined coefficient of variation incorporating the resistance model and the basic variable uncertainties, and all other parameters are as previously defined. Note that the $\mathrm{b}$ values reported in Table 12 were derived based on the resistance model of Eq. (8). The results indicate that, based on the material and geometric statistical parameters adopted herein, the required value of $\gamma_{\mathrm{M} 0}$ is larger than the currently adopted value of 1.0 for both of the considered slenderness limits. While adopting the stricter limit of 38 improves the predictions and gives a lower required $\gamma_{\mathrm{M} 0}$, it remains significantly higher than unity. Similar observations also have been made for ordinary strength steels in a parallel study [61]. It should however be noted that, given the dependency of $\gamma_{\mathrm{M} 0}$ on the adopted material and geometric statistical parameters, different $\gamma_{\mathrm{M} 0}$ values may result if different assumptions were made. Furthermore, if the compressed plate width is determined on the basis of the centreline dimensions of the plates, rather than the flat width, improved results are obtained, and a required value of $\gamma_{\mathrm{M} 0}=1.24$ (rather than 1.26) is found for the slenderness limit $\mathrm{c} / \mathrm{t} \varepsilon=38$.

$$
\begin{gathered}
\mathrm{N}_{\mathrm{c}, \mathrm{Rd}}=\frac{\mathrm{Af}_{\mathrm{y}}}{\gamma_{\mathrm{M} 0}} \quad \text { for Class 1,2 and } 3 \text { cross-sections } \\
\mathrm{N}_{\mathrm{c}, \mathrm{Rd}}=\alpha_{\mathrm{c}, \mathrm{Rd}} \mathrm{Af}_{\mathrm{y}} \\
\mathrm{r}_{\mathrm{d}}=\mathrm{br}_{\mathrm{t}} \exp \left(-\mathrm{k}_{\mathrm{d}, \infty} \alpha_{\mathrm{rt}} \mathrm{Q}_{\mathrm{rt}}-\mathrm{k}_{\mathrm{d}, \mathrm{n}} \alpha_{\delta} \mathrm{Q}_{\delta}-0.5 \mathrm{Q}^{2}\right)
\end{gathered}
$$

Assessment of the Class 3 slenderness limit for internal elements in compression based on bending tests and the ability to achieve the elastic moment capacity $\mathrm{M}_{\mathrm{el}}$ has been examined in previous studies for both normal strength [55] 
and high strength [25] steels. In these studies, the Class 3 slenderness limits of both $\mathrm{c} / \mathrm{t} \varepsilon=42$ and 38 were shown to be suitable, and reasons for the improved local buckling performance of cross-sections in bending over those in compression were discussed.

\subsubsection{Class 4 effective width equation}

The compression resistance of a Class 4 cross-section $\mathrm{N}_{\mathrm{c}, \mathrm{Rd}}$ is determined from Eq. 10, where $\mathrm{A}_{\text {eff }}$ is the effective cross-sectional area, $\mathrm{f}_{\mathrm{y}}$ is the yield stress and $\gamma_{\mathrm{M} 0}$ is the partial safety factor. For SHS and RHS with round corners, the effective cross-sectional area $\mathrm{A}_{\mathrm{eff}}$ is obtained as the product of the reduction factor $\rho$ and the gross cross-sectional area of the flat faces $A_{\text {flat }}$ plus the cross-sectional area of the corners. As the reduction factor $\rho$ is a function of the cross-section plate slenderness $\bar{\lambda}_{\mathrm{p}}$, which is in turn a function of the cross-sectional area A and the yield stress $\mathrm{f}_{\mathrm{y}}$, the resistance function can be expressed in a modified format as given by Eq. 11 for the purpose of the reliability analysis performed. Expressing the resistance function in this way complies with the assumption made in the EN 1990 Annex D method that the resistance equation is a function of independent variables. In Eq. 11, $\mathrm{k}$ is the model constant, independent of $\mathrm{A}$ and $\mathrm{f}_{\mathrm{y}}$, and $\mathrm{a}$ and $\mathrm{b}$ are the model parameters that are specific to each test specimen and vary with cross-section slenderness $\bar{\lambda}_{\mathrm{p}}$. Similar procedures to that described in [63] were used to determine the coefficient a used in Eq. 11, while the coefficient $\mathrm{b}$ was conservatively set to unity. The $\gamma_{\mathrm{M} 0}$ value deemed necessary when using Eq. 10 for high strength steels was found to be 1.22. This value is greater than the current $\gamma_{\mathrm{M} 0}$ value of 1.0, though it has been argued in [61] that, given a buckling phenomenon (local buckling) is being considered, it would be more appropriate to use the $\gamma_{\mathrm{M} 1}$ partial safety factor for slender (Class 4) cross-sections, which has a value of 1.1, in EN 1993-1-5 [23]. This approach is recommended herein, pending further investigations. Note also that, as with the assessment of the Class 3 limit, improved results are achieved when using the plate centreline rather than flat width dimensions, yielding a required value of $\gamma_{\mathrm{M} 0}$ of 1.20 (rather than 1.22).

$$
\begin{gathered}
\mathrm{N}_{\mathrm{c}, \mathrm{Rd}}=\frac{\mathrm{A}_{\text {eff }} \mathrm{f}_{\mathrm{y}}}{\gamma_{\mathrm{M} 0}}=\frac{\left(\rho \mathrm{A}_{\text {flat }}+\mathrm{A}_{\text {corner }}\right) \times \mathrm{f}_{\mathrm{y}}}{\gamma_{\mathrm{M} 0}} \text { for Class } 4 \text { cross-sections } \\
\mathrm{N}_{\mathrm{c}, \mathrm{Rd}}=\frac{\mathrm{kf}_{\mathrm{y}}{ }^{\mathrm{a}} \mathrm{A}^{\mathrm{b}}}{\gamma_{\mathrm{M} 0}}
\end{gathered}
$$

\section{Conclusions}

An experimental programme comprising tensile coupon tests on flat and corner materials, measurements of geometric imperfections, full cross-section tensile tests and stub column tests on high strength steel square and rectangular hollow sections was described in this paper. Both hot-rolled and cold-formed HSS sections, including six S460NH and five S690QH hot-rolled section sizes and three S500MC, two S700MC and four S960QC cold-formed section sizes were examined. An assessment of the existing design guidelines for high strength steels given in Eurocode 3, based on the results of tests presented in this paper and those collated from the literature was then performed. The focus was on 1) the material ductility requirements, 2) the Class 3 slenderness limit for internal elements in compression and 3) the effective width formula for Class 4 internal elements in compression. As far as the ductility of HSS materials is concerned, it was shown that high strength steels with yield strengths in the range of $460-700 \mathrm{~N} / \mathrm{mm}^{2}$, satisfy both the existing more relaxed limits of EN 1993-1-12 as well as the stricter limits of EN 1993-1-1 related to the ultimate to yield strength ratio, the strain at fracture and the ultimate to yield strain ratio. Moreover, it was also found that the EN1993-1-12 relaxed limits for the ultimate to yield strength ratio and the strain at fracture are also generally satisfied by the higher strength materials with yield strengths above $700 \mathrm{~N} / \mathrm{mm}^{2}$; this was however not the case for the ultimate to yield strain ratios. For the Class 3 slenderness limit for internal elements in compression and the Class 4 effective width formula, reliability analyses indicated that a partial safety factor $\gamma_{\mathrm{M} 0}$ greater that the currently adopted value of unity is required for high strength steels. It should however be noted that similar observations were also recently 
made for normal strength steel [61] and that different assumptions regarding the statistical distributions of material and geometric properties could yield different results.

\section{Acknowledgements}

This research has received funding from the Research Fund for Coal and Steel (RFCS) under grant agreement No. RFSR CT 2012-00028 and RFSR CT 2012-00036. The test specimens were provided by VoestAlpine Krems, Ruukki Metals Oy and V\&M DEUTSCHLAND GMBH, whose support is gratefully acknowledged. The authors would also

like to thank Mr Gordon Herbert, Mr Fillip Kirazov, Mr Isaak Vryzidis, Mr Andreas Kessels and Miss Julia Bauer for their assistance in the experimental part of this research. 


\section{List of symbols}

\begin{tabular}{|c|c|}
\hline $\mathrm{A}$ & Cross-sectional area \\
\hline $\mathrm{A}_{\mathrm{c}}$ & Coupon cross-sectional area \\
\hline$A_{\text {corner }}$ & Cross-sectional area of corner regions \\
\hline$A_{\text {eff }}$ & Effective cross-sectional area \\
\hline$A_{\text {flat }}$ & Cross-sectional area of flat faces \\
\hline $\mathrm{b}$ & Section breadth \\
\hline$b_{\mathrm{cl}}$ & Centreline width \\
\hline $\mathrm{b}_{\mathrm{eq}, \mathrm{cl}}$ & Equivalent centreline width \\
\hline $\mathrm{b}_{\text {eq,flat }}$ & Equivalent flat width \\
\hline$b_{\text {flat }}$ & Flat width \\
\hline $\mathrm{COV}$ & Coefficient of variation \\
\hline $\mathrm{c}$ & Plate flat width \\
\hline $\mathrm{E}$ & Young's modulus \\
\hline $\mathrm{FE}$ & Finite element \\
\hline $\mathrm{f}_{\mathrm{u}}$ & Ultimate tensile stress \\
\hline $\mathrm{f}_{\mathrm{uc}}$ & Ultimate tensile stress of corner coupon \\
\hline $\mathrm{f}_{\mathrm{u}, \mathrm{cs}}$ & Ultimate tensile stress of cross-section \\
\hline $\mathrm{f}_{\mathrm{y}}$ & Yield stress \\
\hline $\mathrm{f}_{\mathrm{yc}}$ & Yield stress of corner coupon \\
\hline $\mathrm{f}_{\mathrm{y}, \mathrm{cs}}$ & Yield stress of cross-section \\
\hline $\mathrm{f}_{\mathrm{y}, \text { mean }}$ & Mean measured material yield stress \\
\hline $\mathrm{f}_{\mathrm{y}, \text { nom }}$ & Nominal material yield stress \\
\hline HSS & High strength steel \\
\hline $\mathrm{h}$ & Section height \\
\hline $\mathrm{k}_{\mathrm{d}, \mathrm{n}}$ & Design fractile factor for $\mathrm{n}$ data points \\
\hline $\mathrm{k}_{\mathrm{d}, \infty}$ & Design fractile factor for $n$ tending to infinity \\
\hline $\mathrm{k}_{\sigma}$ & Plate buckling coefficient \\
\hline $\mathrm{L}$ & Length of specimen \\
\hline $\mathrm{L}_{\mathrm{o}}$ & Standard gauge length \\
\hline $\mathrm{MC}$ & Thermomechanically rolled and cold-formed section \\
\hline $\mathrm{M}_{\mathrm{el}}$ & Elastic moment capacity \\
\hline $\mathrm{N}$ & Axial load \\
\hline $\mathrm{N}_{\mathrm{u}}$ & Ultimate load \\
\hline $\mathrm{N}_{\mathrm{c}, \mathrm{Rd}}$ & Cross-section design compression resistance \\
\hline $\mathrm{NH}$ & Normalised hollow section \\
\hline $\mathrm{n}$ & Number of data points \\
\hline Q & Reliability parameter defined in EN 1990 \\
\hline $\mathrm{QC}$ & Quenched and tempered and cold-formed section \\
\hline $\mathrm{QH}$ & Quenched and tempered hollow section \\
\hline $\mathrm{Q}_{\delta}$ & Reliability parameter defined in EN 1990 \\
\hline $\mathrm{Q}_{\mathrm{rt}}$ & Reliability parameter defined in EN 1990 \\
\hline
\end{tabular}


RHS Rectangular hollow section

$\mathrm{r}_{\mathrm{d}} \quad$ Design resistance

$\mathrm{r}_{\mathrm{e}} \quad$ Experimental resistance

$r_{i} \quad$ Internal corner radius

$\mathrm{r}_{\mathrm{n}} \quad$ Nominal resistance

$\mathrm{r}_{\mathrm{t}} \quad$ Theoretical resistance

SHS Square hollow section

$\mathrm{t} \quad$ Thickness

$\mathrm{V}_{\mathrm{f}_{\mathrm{y}}} \quad$ Coefficient of variation of material yield stress

$\mathrm{V}_{\mathrm{r}} \quad$ Combined coefficient of variation

$\mathrm{V}_{\delta} \quad$ Coefficient of variation of test results relative to resistance model

$\mathrm{Z} \quad$ Area reduction factor

$\mathrm{Z}_{\mathrm{c}} \quad$ Corner coupon area reduction factor

$\alpha_{\delta} \quad$ Weighing factor for $\mathrm{Q}_{\delta}$

$\alpha_{\mathrm{rt}} \quad$ Weighing factor for $\mathrm{Q}_{\mathrm{rt}}$

$\gamma_{\mathrm{M} 0} \quad$ Partial safety factor for cross-section resistance

$\gamma_{\mathrm{M} 1} \quad$ Partial safety factor for member resistance

$\delta \quad$ End-shortening

$\delta_{\mathrm{u}} \quad$ End-shortening at ultimate load

$\varepsilon \quad$ strain and EN 1993-1-1 material parameter $\varepsilon=\sqrt{235 / \mathrm{f}_{\mathrm{y}}}$

$\varepsilon_{\mathrm{f}} \quad$ Plastic strain at fracture

$\varepsilon_{\mathrm{fc}} \quad$ Plastic strain at fracture of corner coupon

$\varepsilon_{\mathrm{f}, \mathrm{cs}} \quad$ Plastic strain at fracture of cross-section

$\varepsilon_{\mathrm{u}} \quad$ Strain at ultimate tensile stress

$\varepsilon_{\mathrm{uc}} \quad$ Strain at ultimate tensile stress of corner coupon

$\varepsilon_{\mathrm{u}, \mathrm{cs}} \quad$ Strain at ultimate tensile stress of cross-section

$\bar{\lambda}_{\mathrm{p}} \quad$ Plate slenderness

$\nu \quad$ Poisson's ratio

$\rho \quad$ Reduction factor

$\sigma_{\mathrm{cr}} \quad$ Elastic buckling stress

$\sigma_{\mathrm{cr}, \mathrm{cs}} \quad$ Elastic buckling stress calculated using Direct Strength method (CUFSM software)

$\omega_{\mathrm{EN}} \quad$ Imperfection amplitude allowance defined by Eurocode

$\omega_{0} \quad$ Measured imperfection amplitude

\section{References}

[1] Billingham J., Sharp J. V., Spurrier J., and Kilgallon P. J. Review of the performance of high strength steels used offshore. Technical report, Cranfield University for Health and Safety Executive, 2003.

[2] Griffis G. L., Axmann G., and Patel B. V. High-strength steel in the long-span retractable roof of reliant stadium. In 2003 NASCC Proceedings. Baltimore, MD; NASCC, 2003.

[3] Pocock G. High strength steel use in Austalia, Japan and the US. The Structural Engineer, 84(21):27-30, 2006.

[4] Höglund T., Collin P., Müller C., Schröter F., and Miazzon A. Chapter 5.5 - Examples and applications. In Use and application of high-performance steels for steel structures. International Association for Bridge and Structural Engineering (IABSE), 2005. 
[5] EN 1993-1-1. Eurocode 3: Design of steel structures. Part 1-1: General rules and rules for buildings. European Committee for Standardization (CEN), 2005.

[6] EN 1993-1-12. Eurocode 3: Design of steel structures. Part 1-12: Additional rules for the extension of EN 1993 up to steel grades S700. European Committee for Standardization (CEN), 2006.

[7] Samuelsson A. and Schröter F. Chapter 5.1 - Production processes, mechanical and chemical properties, fabrication properties. In Use and application of high-performance steels for steel structures. International Association for Bridge and Structural Engineering (IABSE), 2005.

[8] Sivakumaran S. K. Relevance of Y/T ratio in the design of steel structures. In Proceedings of International Symposium on Applications of High Strength Steels in Modern Constructions and Bridge-Relationship of Design specifications, Safety and Y/T ratio. Beijing, pages 54-63, 2008.

[9] Fukumoto Y. New constructional steels and structural stability. Engineering Structures, 18(10):786-791, 1998.

[10] Langenberg P. Relation between design safety and Y/T ratio in application of welded high strength structural steels. In Proceedings of International Symposium on Applications of High Strength Steels in Modern Constructions and Bridge-Relationship of Design specifications, Safety and Y/T ratio. Beijing, pages 28-46, 2008.

[11] Nishino F., Ueda Y., and Tall L. Experimental investigation of the buckling plates with residual stress. Technical report, Firtz Engineering Laboratory Report No. 290.3, Lehigh University, Bethlehem, Pennsylvania, USA, 1966.

[12] Rasmussen K. J. R. and Hancock G. J. Plate slenderness limits for high strength steel sections. Journal of Constructional Steel Research, 23:73-96, 1992.

[13] Kim D. K., Lee C. H., Han K. H., Kim J. H., Lee S. E., and Sim H. B. Strength and residual stress evaluation of stub columns fabricated from $800 \mathrm{MPa}$ high-strength steel. Journal of Constructional Steel Research, 102:111-120, 2014.

[14] EN 1990:2002. Eurocode : Basis of structural design. European Committee for Standardization (CEN), 2002.

[15] EN 10210-2:2006. Hot finished structural hollow sections of non-alloy and fine grain steels. Part 2: Tolerances, dimensions and sectional properties. European Committee for Standardization (CEN), 2006.

[16] EN 10149-2:2013. Hot rolled flat products made of high yield strength steels for cold forming. Part 2: Technical delivery conditions for thermomechanically rolled steels. European Committee for Standardization (CEN), 2013.

[17] BS EN ISO 6892-1:2009. British Standard: Metallic materials - Tensile testing. Part 1: Method of test at ambient temperature. The Standards Policy and Strategy Committee, 2009.

[18] Afshan S., Rossi B., and Gardner L. Strength enhancements in cold-formed structural sections - Part I: Material testing. Journal of Constructional Steel Research, 83:177-188, 2013.

[19] Zhao O., Gardner L., and Young B. Structural performance of stainless steel circular hollow sections under combined axial load and bending part 1: Experiments and numerical modelling. Thin-Walled Structures, 101:231-239, 2016.

[20] Huang Y. and Young B. The art of coupon tests. Journal of Constructional Steel Research, 96:159-175, 2014.

[21] Schafer B. W. and Peköz T. Computational modeling of cold-formed steel: characterizing geometric imperfections and residual stresses. Journal of Constructional Steel Research, 47:193-210, 1998. 
[22] EN 10219-2:2006. Cold formed welded structural hollow sections of non-alloy and fine grain steels. Part 2: Tolerances, dimensions and sectional properties. European Committee for Standardization (CEN), 2006.

[23] EN 1993-1-5. Eurocode 3: Design of steel structures. Part 1-5: Plated structural elements. European Committee for Standardization (CEN), 2006.

[24] EN 1993-1-3. Eurocode 3: Design of steel structures. Part 1-3: General rules-Supplementary rules for cold-formed members and sheeting. European Committee for Standardization (CEN), 2009.

[25] Wang J., Afshan S., Gkantou M., Theofanous M., Baniotopoulos C, and Gardner L. Flexural behaviour of hot-finished high strength steel square and rectangular hollow sections. Journal of Constructional Steel Research, 121:97-109, 2016.

[26] Theofanous M., Chan T. M., and Gardner L. Flexural buckling of strainless steel oval hollow sections. Engineering Structures, 47:776-787, 2009.

[27] Yuan B. Local buckling of high strength steel W-shaped sections. Technical report, Open Access Dissertations and Theses, Paper 4059, 1997.

[28] Shi G., Ban H. Y., and Bijlaard F. S. K. Tests and numerical study of ultra-high strength steel columns with end restraints. Journal of Constructional Steel Research, 70:236-247, 2012.

[29] Ban H. Y., Shi G., Shi Y. J., and Wang Y. Q. Overall buckling behavior of $460 \mathrm{MPa}$ high strength steel columns: Experimental investigation and design method. Journal of Constructional Steel Research, 74:140-150, 2012.

[30] Ban H. Y., Shi G., Shi Y. J., and Bradford M. A. Experimental investigation of the overall buckling behaviour of $960 \mathrm{MPa}$ high strength steel columns. Journal of Constructional Steel Research, 88:256-266, 2013.

[31] Wang Y. B., Li G. Q., Chen S. W., and Sun F. F. Experimental and numerical study on the behavior of axially compressed high strength steel box-columns. Engineering Structures, 58:79-91, 2014.

[32] Lee C. H., Han K. H., Uang C. M., Kim D. K., Park C. H., and Kim J. H. Flexural strength and rotation capacity of I-shaped beams fabricated from 800-MPa steel. Journal of Structural Engineering, ASCE, 139(6):1043-1058, 2013.

[33] Beg D. and Hladnik L. Slenderness limit of Class 3 I cross-sections made of high strength steel. Journal of Constructional Steel Research, 38(3):201-217, 1996.

[34] Langenberg P., Niessen T., and Dahl W. Bruch- und Verformungsverhalten von hochfesten Stäehlen mit Streckgrenzen von 690 bis 890 MPA. Stahlbau, 69:291-283, 2000. In German.

[35] Wang Y. B., Li G. Q., Cui W., Chen S. W., and Sun F. F. Experimental investigation and modeling of cyclic behavior of high strength steel. Journal of Constructional Steel Research, 104:37-48, 2015.

[36] Gho W. M. and Liu D. L. Flexural behaviour of high-strength rectangular concrete-filled steel hollow sections. Journal of Constructional Steel Research, 60(11):1681-1696, 2004.

[37] Sedlacek G., Müller C., and Nussbanumer A. Chapter 5.1 - Toughness requirements in structural applications. In Use and application of high-performance steels for steel structures. International Association for Bridge and Structural Engineering (IABSE), 2005.

[38] Salih E. L., Gardner L., and Nethercot D. A. Numerical investigation of net section failure in stainless steel bolted connections. Journal of Constructional Steel Research, 66(12):1455-1466, 2010. 
[39] Johansson B. and Collin P. Eurocode for high strength steel and applications in construction. In In: Super-high strength steels, International Conference Super-High Strength Steels., 2005.

[40] P758. Verbesserte Ausnutzung der Festigkeiten hochfester Druckbehaelterstaehle durch Erfassung des Grenzzustands der Tragfaehigkeit mit Hilfe der Fliess bruchmechanik. Technical report, Final report, FOSTA - Forschungsvereinigung Stahlanwendung e.V., 2010.

[41] ULCF. Ultra low cycle fatigue of steel under cyclic high-strain loading conditions. Technical report, Final report, RFCS - Research Fund for Coal and Steel, 2015.

[42] RUOSTE. Rules on high strength steel. Technical report, Final report, RFCS - Research Fund for Coal and Steel, 2017.

[43] Schaffrath S., Schillo N., and Feldmann M. Derivation of strain requirements for high strength steel using Johnson Cook Model. In Nordic Steel Construction Conference 2015, Tampere, 2015.

[44] Foster A. S. J., Gardner L., and Wang Y. Practical strain-hardening material properties for use in deformation-based structural steel design. Thin-Walled Structures, 92:115-129, 2015.

[45] Usami T. and Fukumoto Y. Welded box compression members. Journal of Structural Engineering, ASCE, 110(10):2457-2470, 1984.

[46] Gao L., Sun H. C., Jin F. N., and Fan H. L. Load-carrying capacity of high-strength steel box-sections I:Stub columns. Journal of Constructional Steel Research, 65:918-924, 2009.

[47] Yoo J. H., Kim J. W., Yang J. G., Kang J. W., and Lee M. J. Local buckling in the stub columns fabricated with HSA800 of high performance steel. International Journal of Steel Structures, 13(3):445-458, 2013.

[48] Shi G., Zhou W. J., Bai Y., and Lin C. C. Local buckling of $460 \mathrm{MPa}$ high strength steel welded section stub columns under axial compression. Journal of Constructional Steel Research, 100:60-70, 2014.

[49] Sakino K., Nakahara H., Morino S., and Nishiyama I. Behavior of centrally loaded concrete-filled steel-tube short columns. Journal of Structural Enigneering, 130(2):180-188, 2004.

[50] Im S. W., Kim Y. S., and Chang I. H. A study on the characteristics of SM570TMC plates in compression members. Journal of Korean Society of Steel Construction, 17(3):357-363, 2005.

[51] Im S. W., Ko S. K., and Chang I. H. A study on the characteristics of high tensile strength steel (SM570) plates in compression members. Journal of Korean Society of Steel Construction, 13(3):223-232, 2001.

[52] Lee K., Lee M. J., Oh Y. S., Yang Y., and Oh K. A comparative study on stub columns with various steel grades subjected to concentric axial loading. International Journal of Steel Structures, 15(1):103-114, 2015.

[53] Zhao X. L. and Hancock G. J. Tests to determine plate slenderness limits for cold-formed rectangular hollow sections of grade C450. Journal of The Australian Steel Institute, 25(4):1-16, 1991.

[54] Hu S. D., Ye B., and Li L. X. Material properties of thick-wall cold-rolled welded tube with a rectangular or square hollow section. Construction and Building Materials, 25(5):2683-2689, 2011.

[55] Gardner L., Saari N., and Wang F. C. Comparative experimental study of hot-rolled and cold-formed rectangular hollow sections. Thin-Walled Structures, 48(7):495-507, 2010.

[56] Elchalakani M., Zhao X. L., and Grzebieta R. Tests on concrete filled double-skin (CHS outer and SHS inner) composite short columns under axial compression. Thin-Walled Structures, 40:415-411, 2002. 
[57] Seif M. and Schafer B. W. Local buckling of structural steel shapes. Journal of Constructional Steel Research, 66(10):1232-1247, 2010.

[58] Li Z. and Schafer B.W. Buckling analysis of cold-formed steel members with general boundary conditions using CUFSM: conventional and constrained finite strip methods. In Proceedings of the 20th International Specialty Conference on Cold-Formed Steel Structures Saint Louis, Missouri, USA, November, 2010, 2010.

[59] European Steel Design Education Program ESDEP Course. Lecture 7.2 - Cross-Section Classification.

[60] Taras A., Greiner R., and Unterweger H. Proposal for amended rules for member buckling and semi-compact cross-section design. Technical report, Consolidated version of documents of the same title submitted to the SC3 Evolution Group 1993-1-1, Paris, 2013.

[61] Schillo N., Taras A., and Feldmann M. Derivation of local buckling resistance curve and safety factor for mild and high strength steels. Engineering structures. In preparation.

[62] Byfield M. P. and Nethercot D. A. Material and geometric properties of structural steel for use in design. The Structural Engineer, 75(21):363-367, 1997.

[63] Afshan S., Francis P., Baddoo N. R., and Gardner L. Reliability analysis of structural stainless steel design provisions. Journal of Constructional Steel Research, 114:293-304, 2015.

\section{Figures}

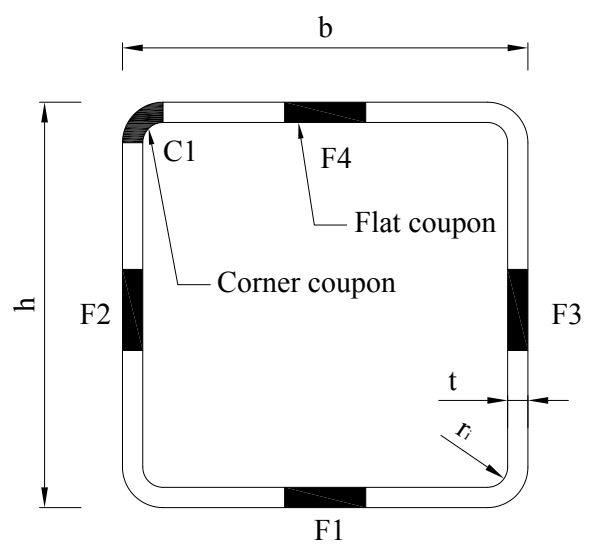

(a) Hot-finished section

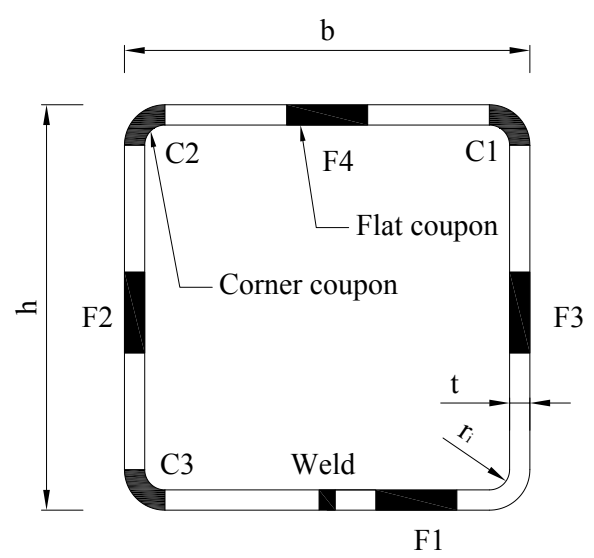

(b) Cold-formed section

Figure 1: Location of flat and corner coupons and definition of cross-section symbols 


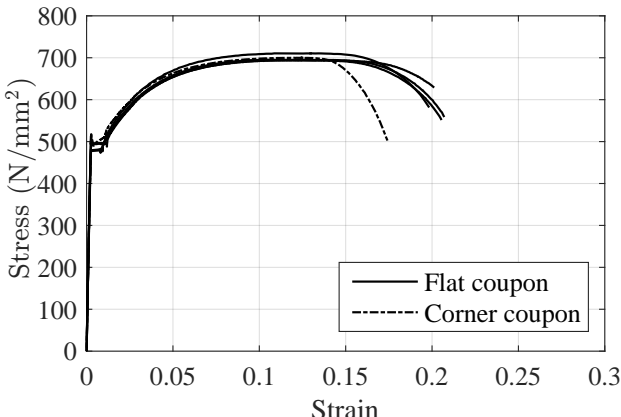

(a) $\mathrm{S} 460 \mathrm{NH}$

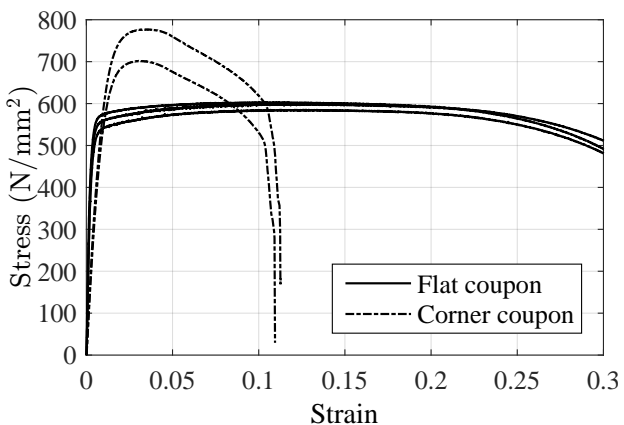

(c) $\mathrm{S} 500 \mathrm{MC}$

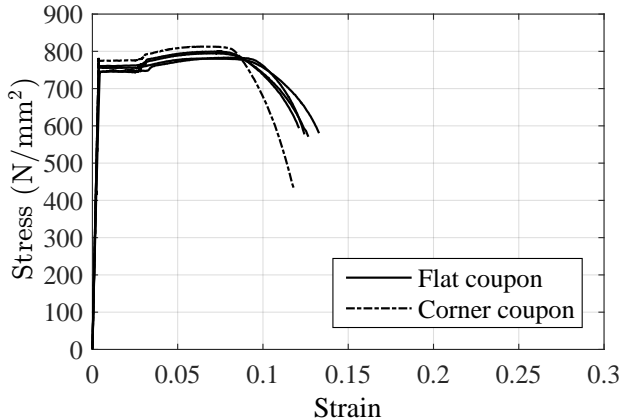

(b) $\mathrm{S} 690 \mathrm{QH}$

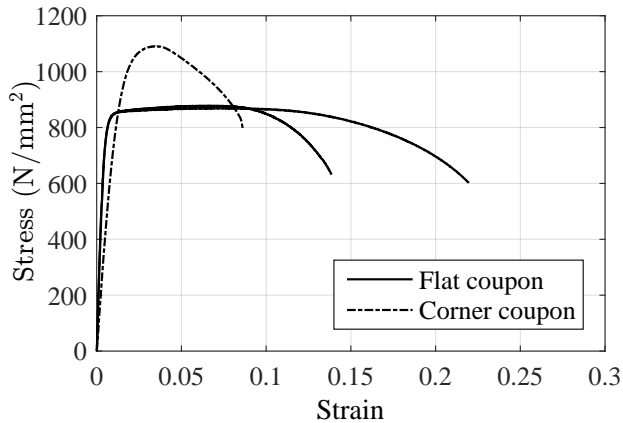

(d) S700MC

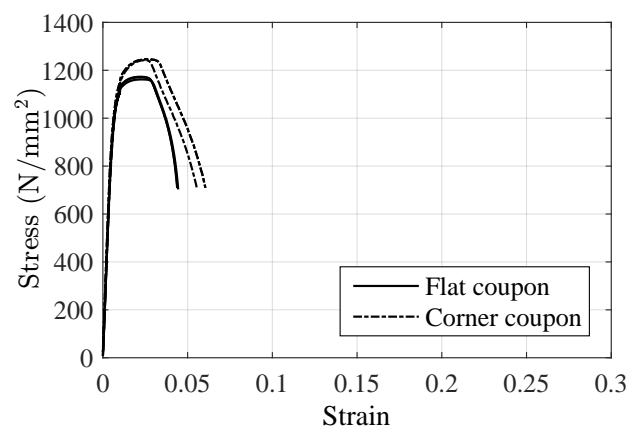

(e) S960QC

Figure 2: Typical flat and corner stress-strain curves for the different tested high strength steel grades 


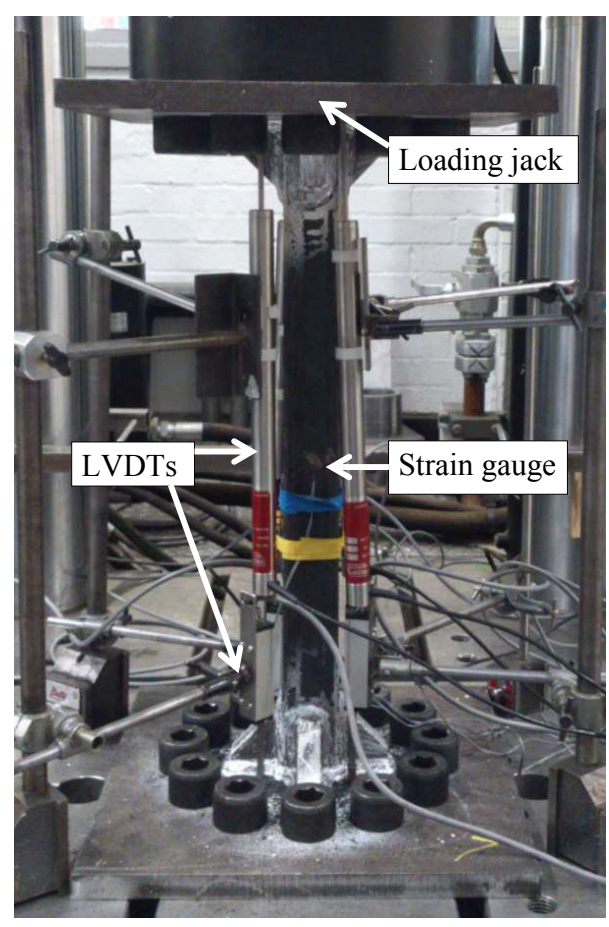

(a) Test set-up

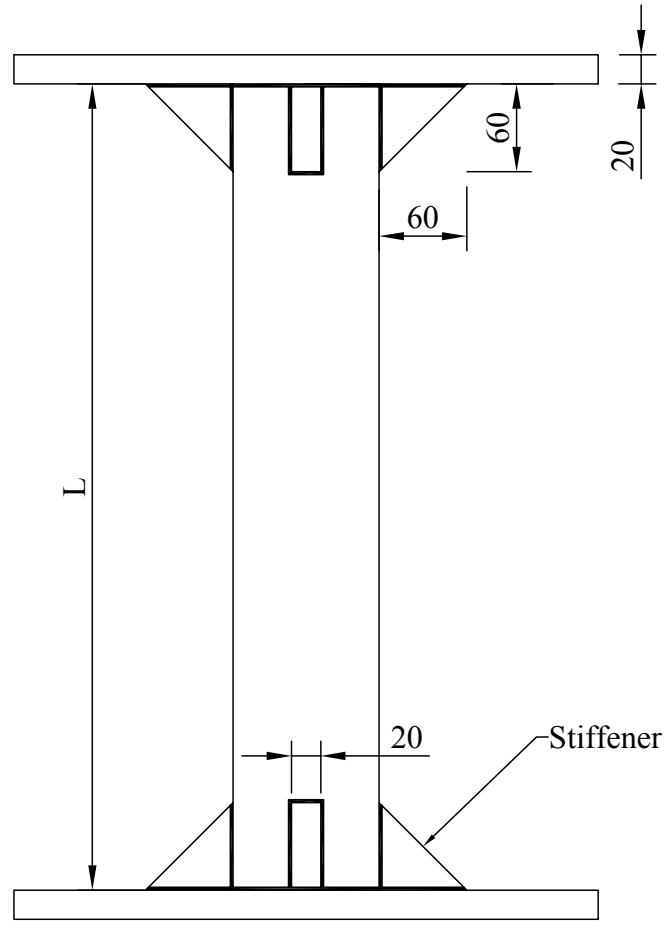

(b) Details of fabricated specimens (dimensions in $\mathrm{mm}$ )

Figure 3: Test set-up and details of full cross-section tensile test specimens.

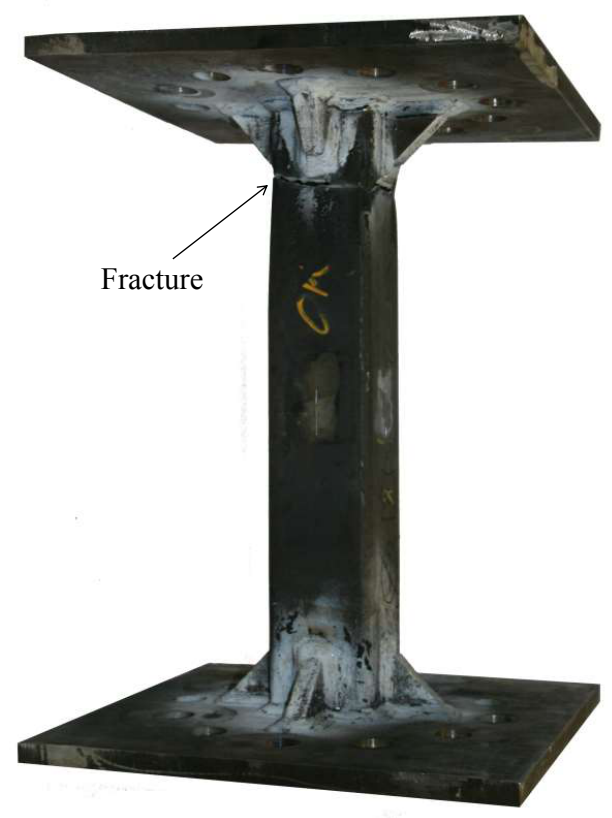

(a) S690 SHS $100 \times 100 \times 5.6$

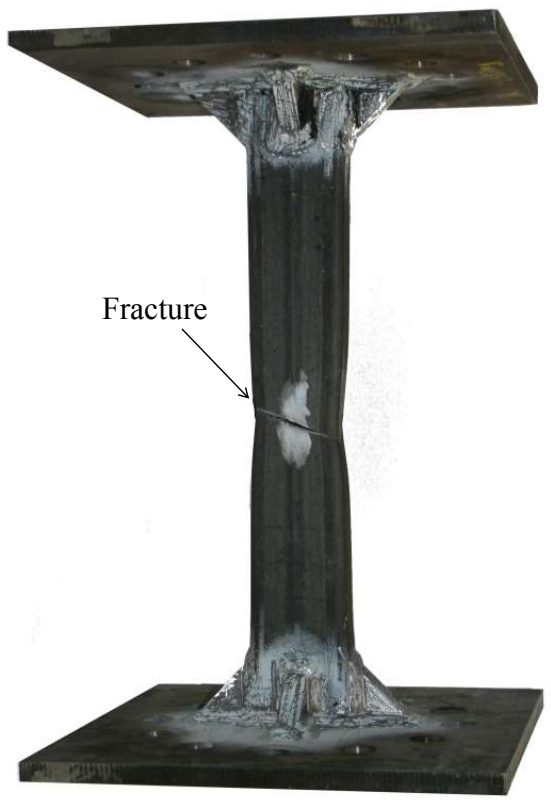

(b) S460 SHS $90 \times 90 \times 3.6$

Figure 4: Typical failure modes of full cross-section tensile test specimens: a) fracture near welded end; b) fracture near mid-height 


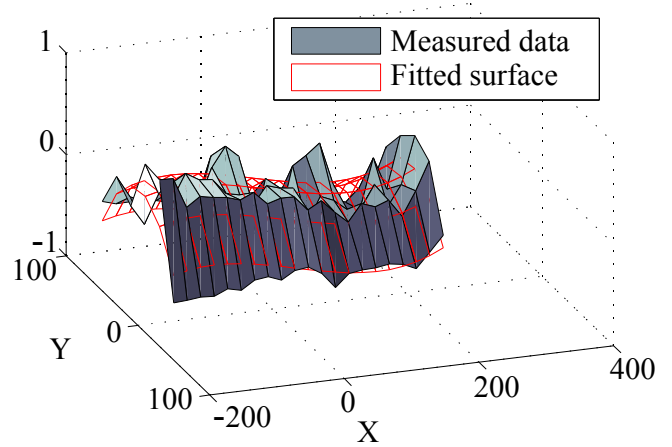

(a) Face1

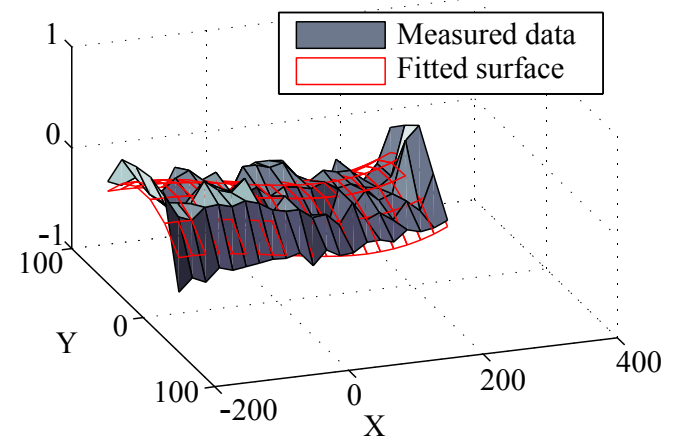

(c) Face3

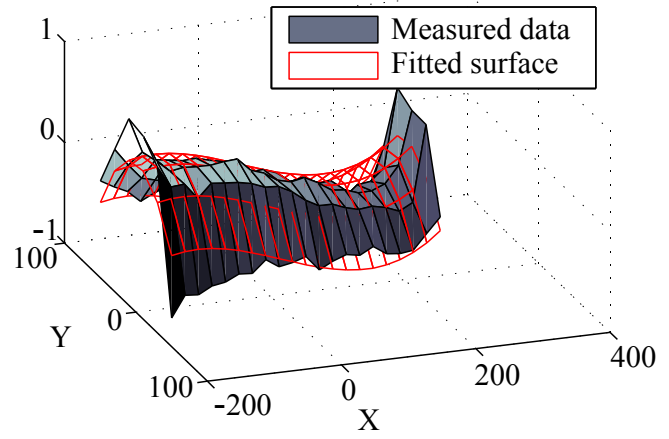

(b) Face2

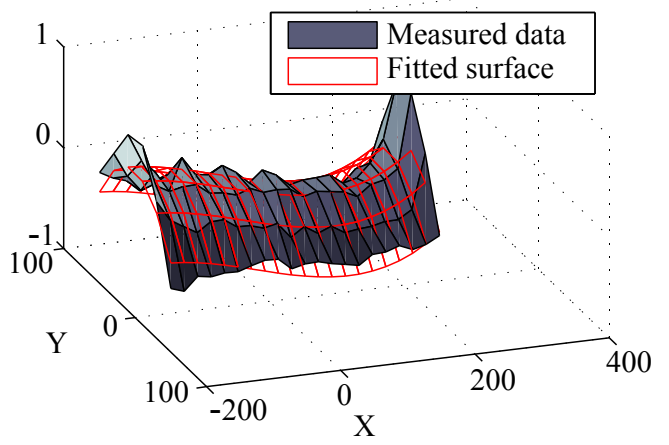

(d) Face4

Figure 5: Local geometric imperfection measurements and best-fit surfaces for the SHS $120 \times 120 \times 4$ S960QC specimen: a) Face 1; b) Face 2; c) Face 3; d) Face 4 - Faces 1, 2, 3 and 4 are as defined in Figure 1

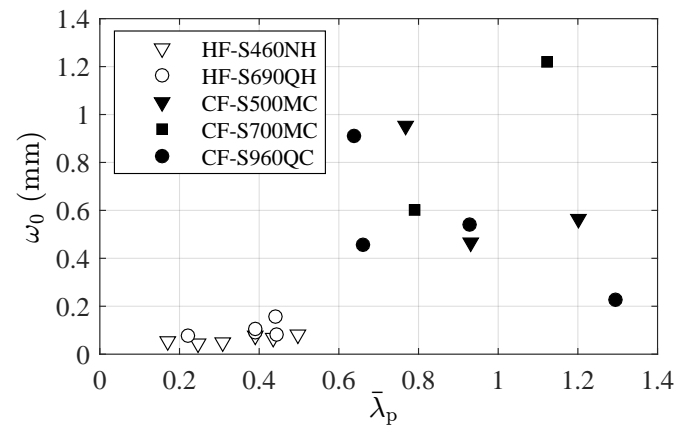

(a) Imperfection amplitude

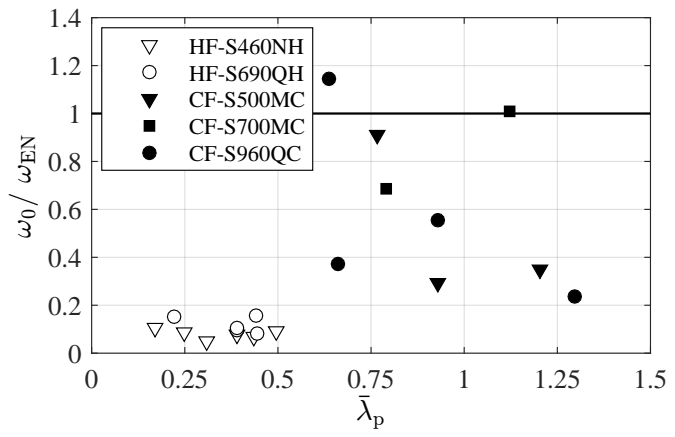

(b) Comparison with EN fabrication requirement

Figure 6: Variation of local geometric imperfections with plate slenderness: a) Imperfection amplitude; b) Comparison with Eurocode fabrication requirement $[15,22]$ 


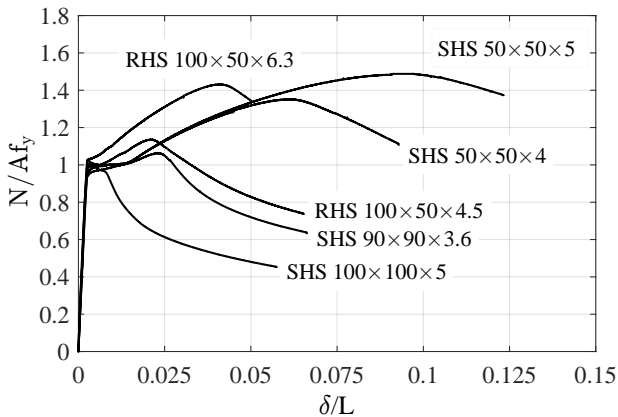

(a) $\mathrm{S} 460 \mathrm{NH}$

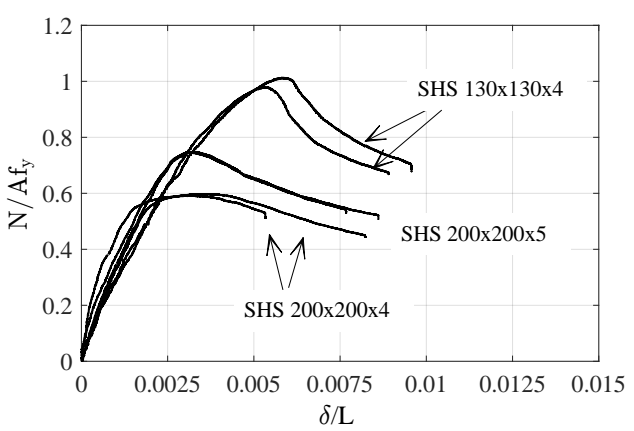

(c) $\mathrm{S} 500 \mathrm{MC}$

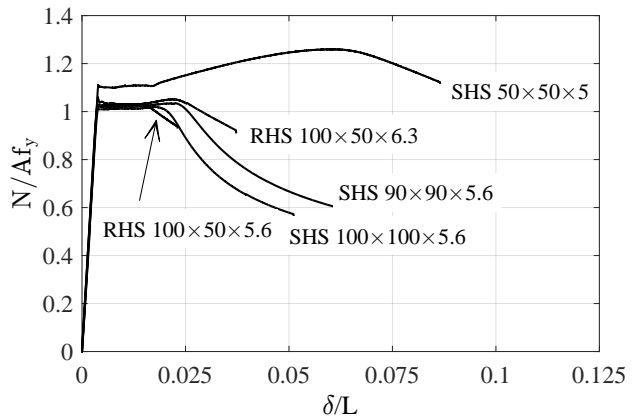

(b) $\mathrm{S} 690 \mathrm{QH}$

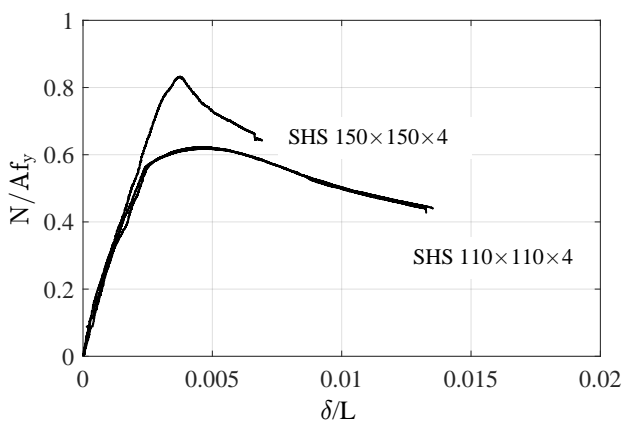

(d) $\mathrm{S} 700 \mathrm{MC}$

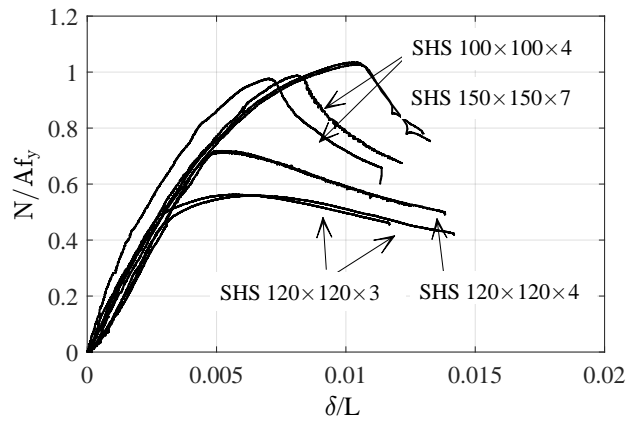

(e) S960QC

Figure 7: Stub column normalised load end-shortening curves: a) S460NH; b) S690QH; c) S500MC; d) S700MC; e) S960QC 


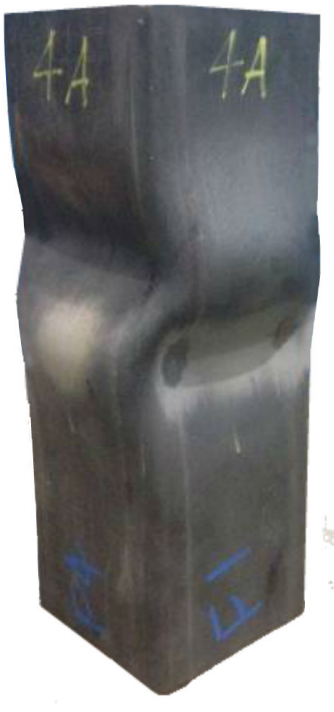

(a) Local buckling

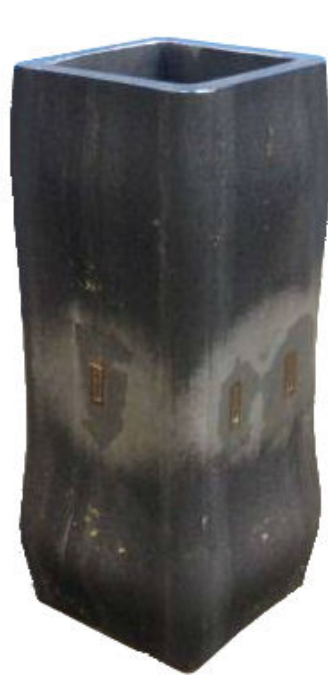

(b) Elephant foot buckling

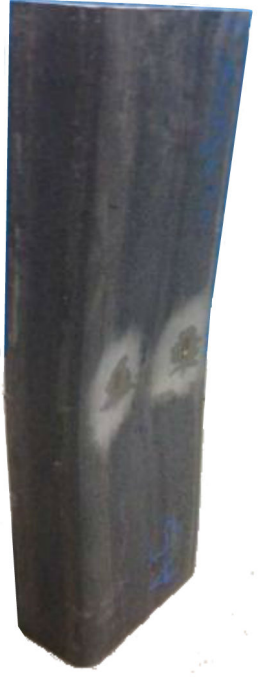

(c) Local + global buckling

Figure 8: Typical stub column failure modes: a) local buckling; b) elephant foot buckling; c) local+global buckling

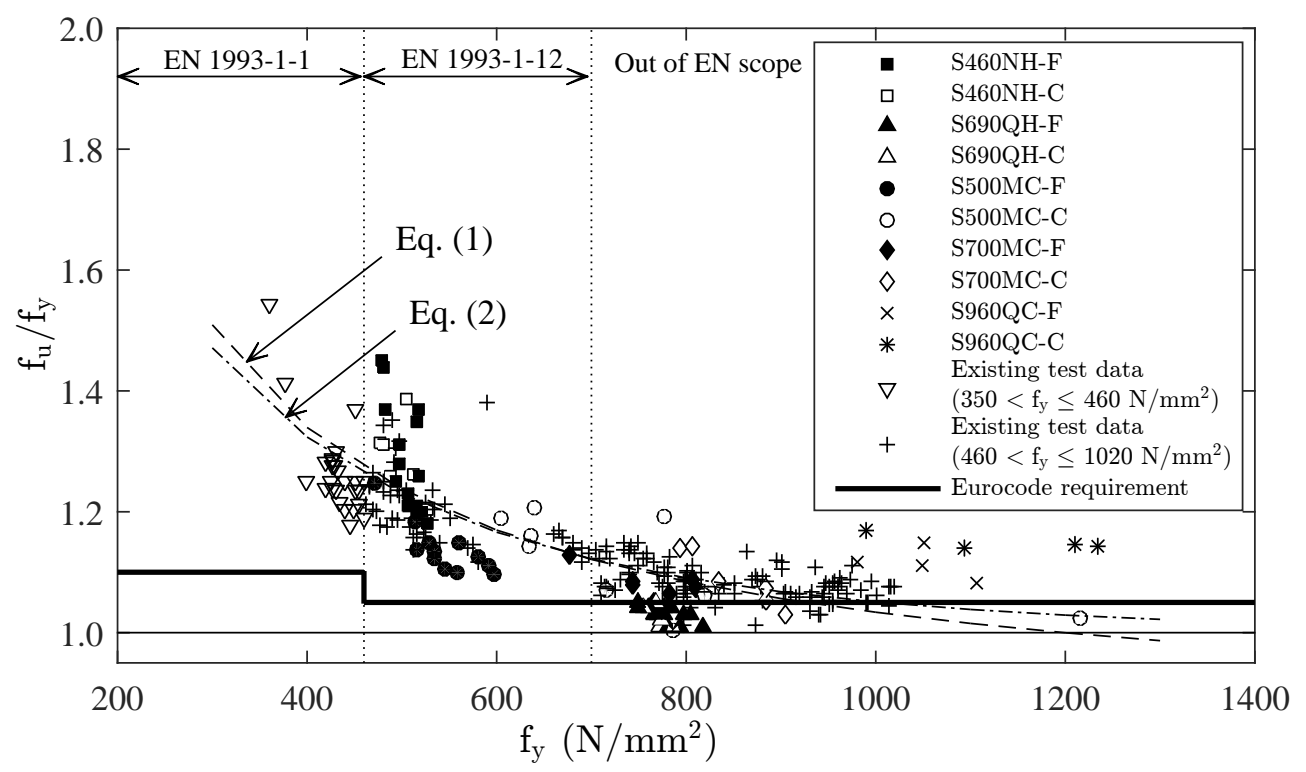

Figure 9: Assessment of the $f_{u} / f_{y}$ ductility limits in Eurocode 3 


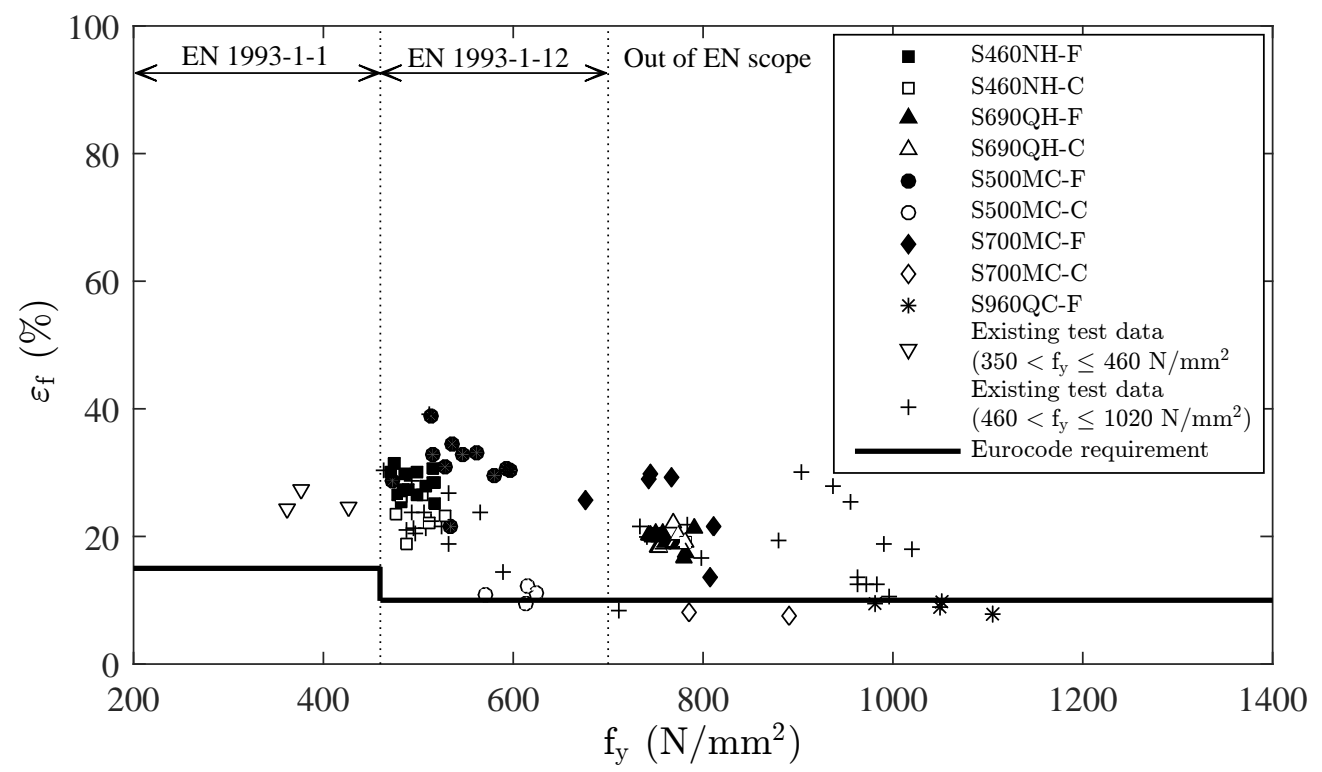

Figure 10: Assessment of the $\varepsilon_{\mathrm{f}}$ ductility limits in Eurocode 3

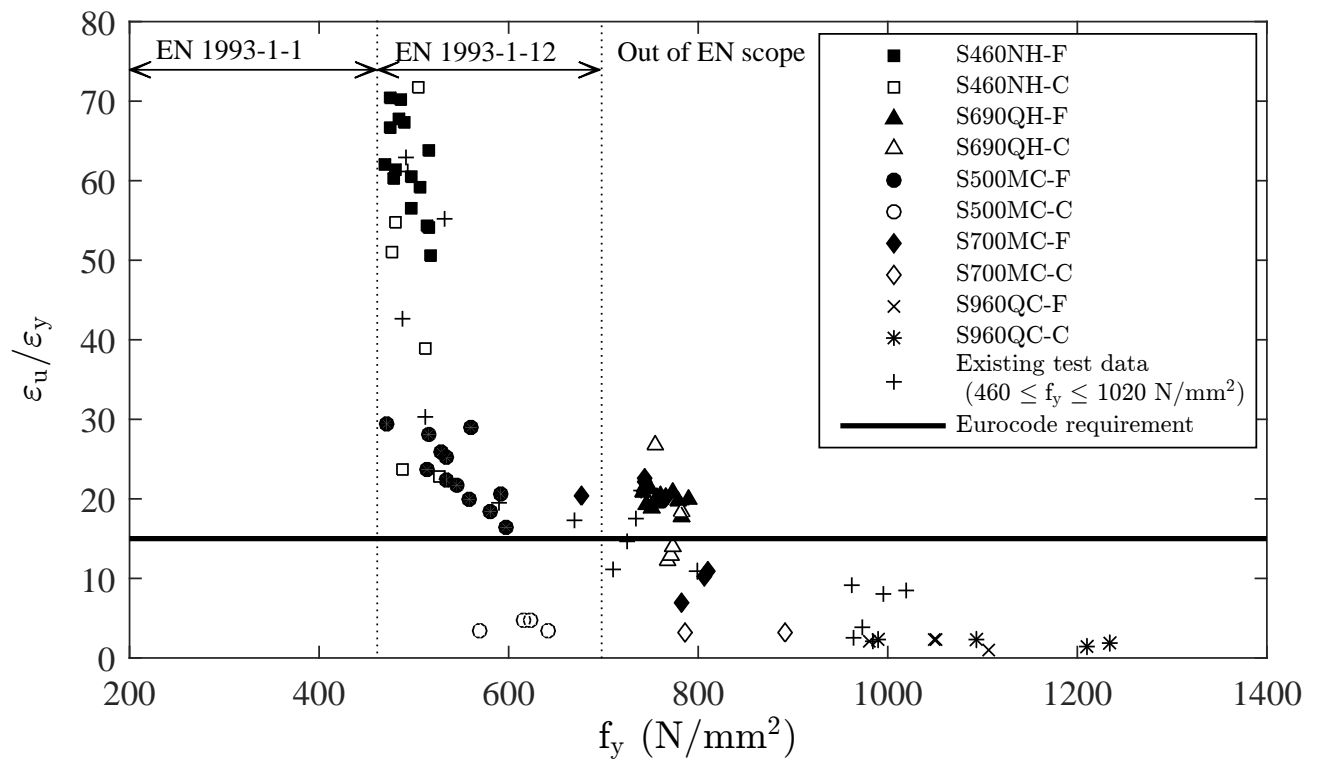

Figure 11: Assessment of the $\varepsilon_{\mathrm{u}} / \varepsilon_{\mathrm{y}}$ ductility limits in Eurocode 3 


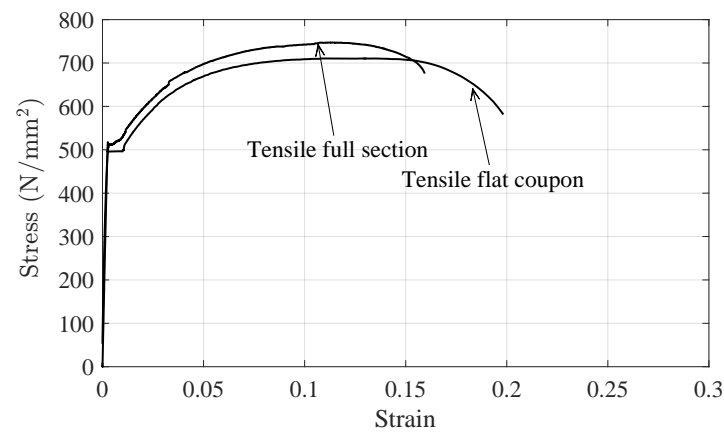

(a) S460 RHS $100 \times 50 \times 6.3$

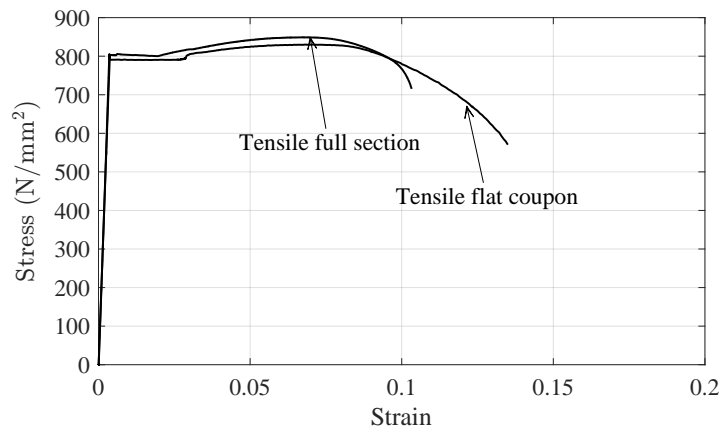

(b) S690 RHS $100 \times 50 \times 6.3$

Figure 12: Comparison of results from full cross-section tensile tests and tensile flat coupon tests

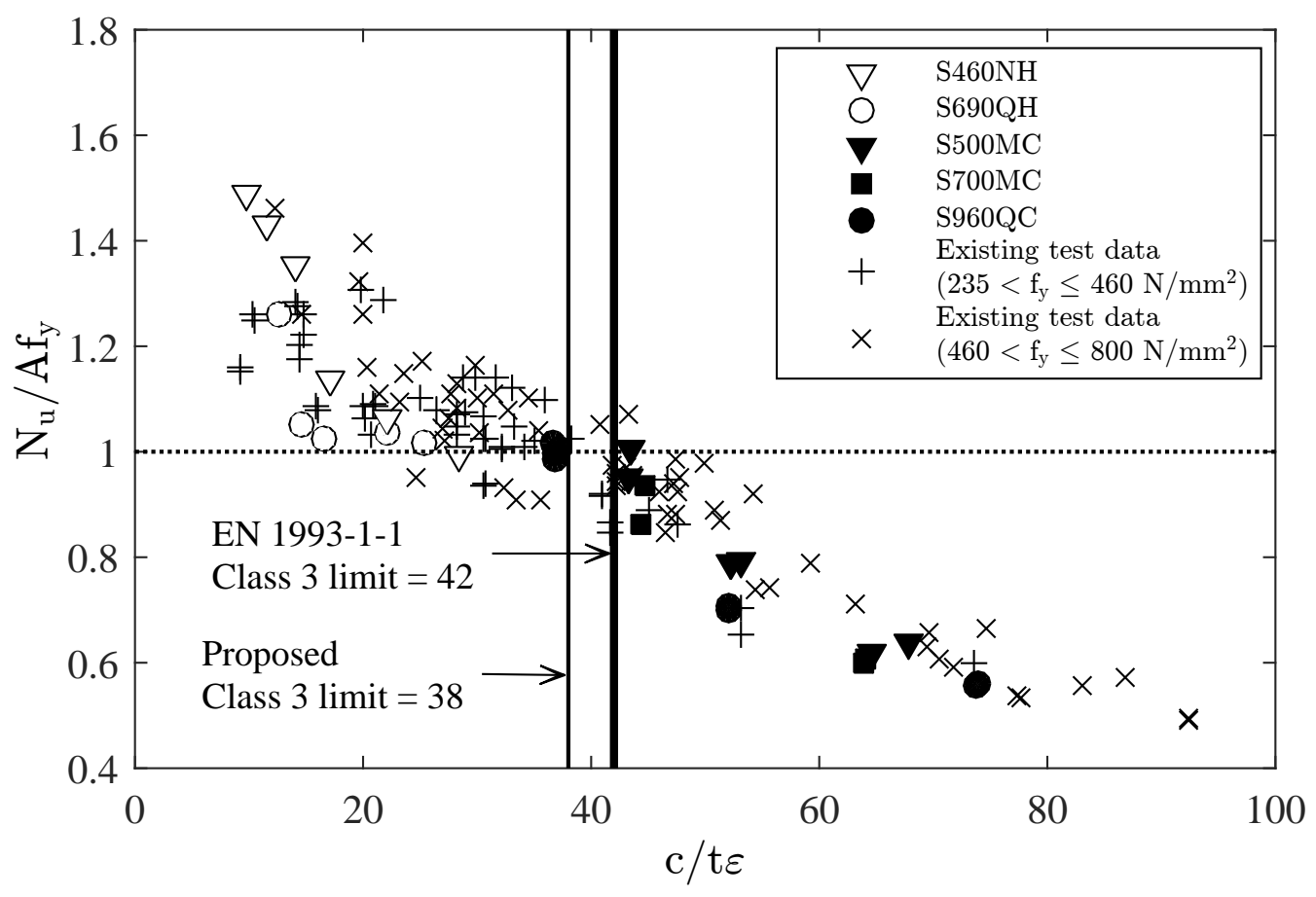

Figure 13: Assessment of Class 3 slenderness limit for internal elements in compression 


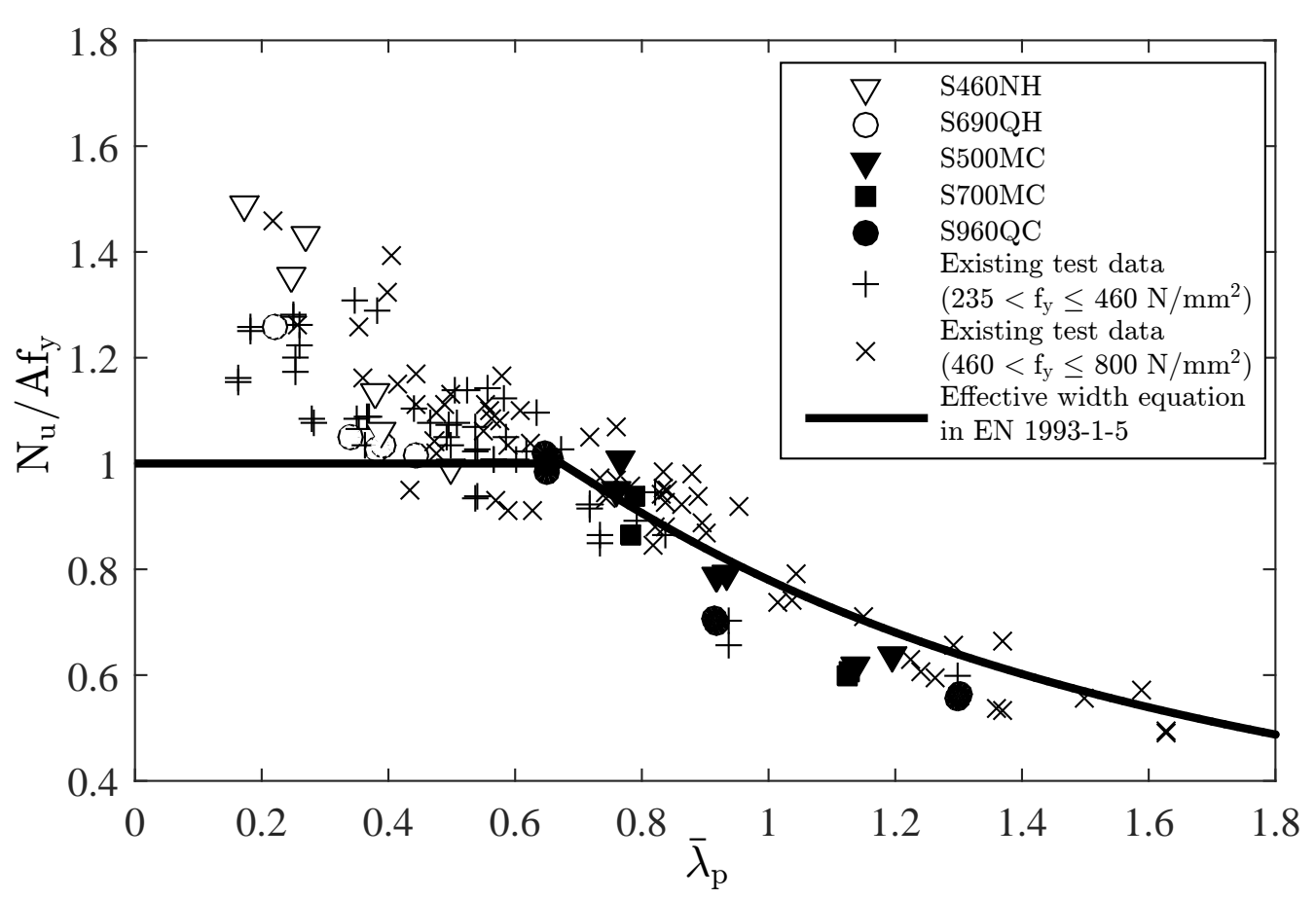

Figure 14: Assessment of Eurocode effective width equation for internal elements in compression

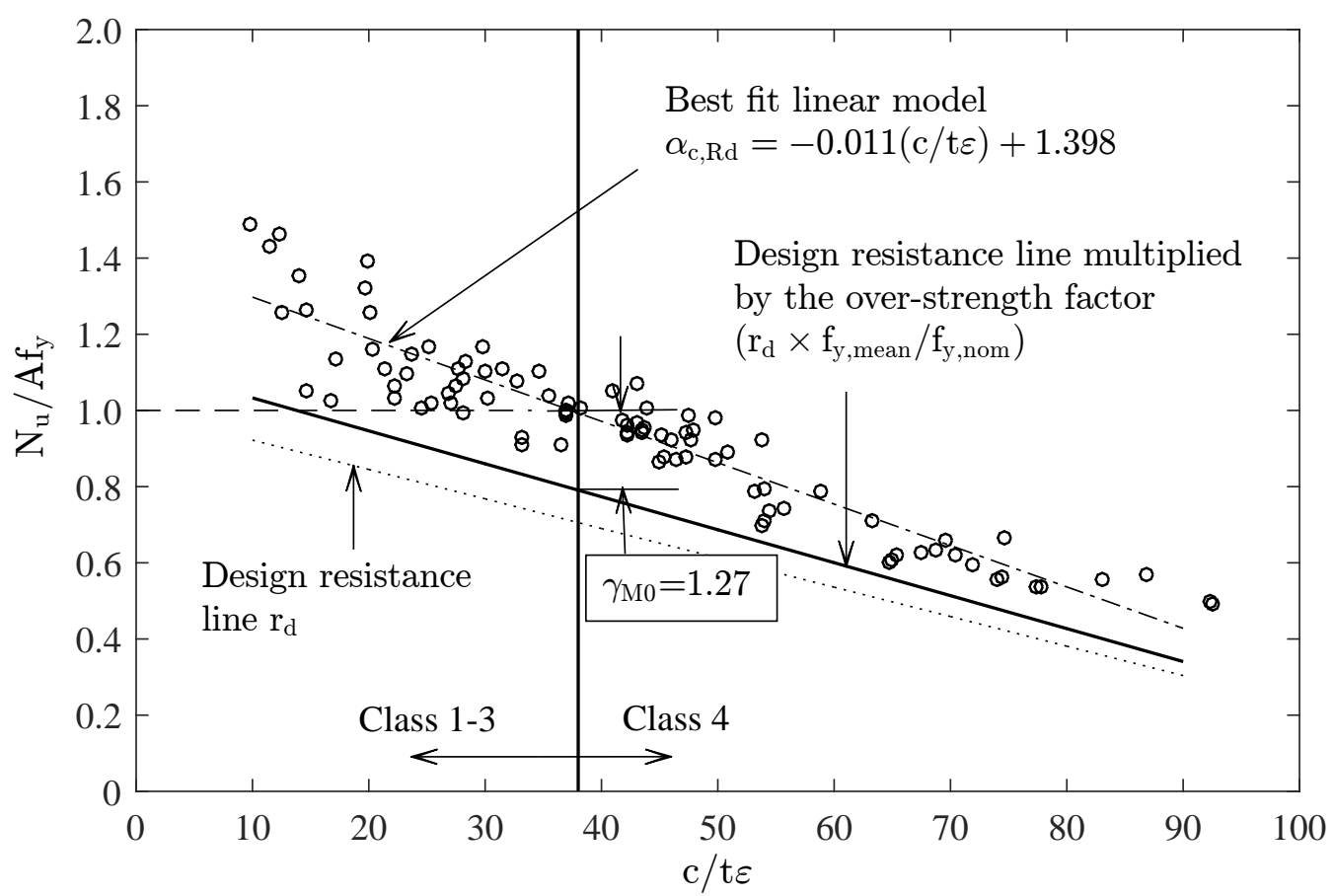

Figure 15: Determination of $\gamma_{\mathrm{M} 0}$ using test results for Class 3 slenderness limit of 38 


\section{Tables}

Table 1: Chemical composition of tested specimens

\begin{tabular}{lllllllllllllllll}
\hline Grade & $\mathrm{C}$ & $\mathrm{Si}$ & $\mathrm{Mn}$ & $\mathrm{P}$ & $\mathrm{S}$ & $\mathrm{Cu}$ & $\mathrm{Cr}$ & $\mathrm{Ni}$ & $\mathrm{Mo}$ & $\mathrm{V}$ & $\mathrm{Ti}$ & $\mathrm{Nb}$ & $\mathrm{B}$ & $\mathrm{Al}$ \\
& $(\%)$ & $(\%)$ & $(\%)$ & $(\% \circ)$ & $(\%)$ & $(\%)$ & $(\%)$ & $(\%)$ & $(\%)$ & $(\%)$ & $(\%)$ & $(\%)$ & $(\%)$ & $(\%)$ \\
\hline S460NH & 0.15 & 0.37 & 1.53 & 0.17 & 0.01 & 0.02 & 0.07 & 0.60 & 0.30 & 0.10 & 0.03 & 0.01 & - & - \\
$\mathrm{S} 690 \mathrm{QH}$ & 0.15 & 0.28 & 1.50 & 0.10 & 0.02 & 0.02 & 0.67 & 1.20 & 2.10 & 0.07 & 0.04 & 0.31 & 0.003 & 0.30 \\
$\mathrm{~S} 500 \mathrm{MC}$ & 0.06 & 0.18 & 1.50 & 0.12 & 0.02 & 0.01 & 0.03 & 0.30 & 0.07 & 0.05 & - & 0.31 & - & 0.42 \\
S700MC & 0.06 & 0.26 & 1.84 & 0.12 & 0.03 & 0.01 & 0.03 & 0.65 & 0.10 & 0.01 & 1.10 & 0.61 & 0.002 & 0.36 \\
S960QC & 0.09 & 0.20 & 1.07 & 0.08 & 0.03 & 0.02 & 1.04 & 0.70 & 1.27 & 0.01 & 0.34 & 0.70 & 0.020 & 0.32 \\
\hline
\end{tabular}

Table 2: Mechanical properties as stated in the mill certificates

\begin{tabular}{|c|c|c|c|c|c|}
\hline \multicolumn{2}{|c|}{ Steel grade } & \multirow{2}{*}{$\begin{array}{l}\text { Cross-section } \\
\text { SHS } 50 \times 50 \times 5\end{array}$} & \multirow{2}{*}{$\begin{array}{l}\mathrm{f}_{\mathrm{y}, \mathrm{mill}} \\
\left(\mathrm{N} / \mathrm{mm}^{2}\right) \\
473\end{array}$} & \multirow{2}{*}{$\begin{array}{l}\mathrm{f}_{\mathrm{u}, \text { mill }} \\
\frac{\left(\mathrm{N} / \mathrm{mm}^{2}\right)}{615}\end{array}$} & \multirow{2}{*}{$\begin{array}{l}\varepsilon_{\mathrm{f}, \mathrm{mill}} \\
\frac{(\%)}{26.5}\end{array}$} \\
\hline \multirow{11}{*}{ 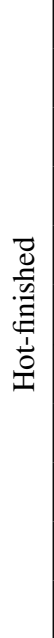 } & \multirow{6}{*}{ S460NH } & & & & \\
\hline & & SHS $50 \times 50 \times 4$ & 524 & 639 & 33.0 \\
\hline & & SHS $100 \times 100 \times 5$ & 492 & 619 & 29.0 \\
\hline & & SHS $90 \times 90 \times 3.6$ & 463 & 656 & 25.5 \\
\hline & & RHS $100 \times 50 \times 6.3$ & 495 & 668 & 23.5 \\
\hline & & RHS $100 \times 50 \times 4.5$ & 505 & 642 & 27.5 \\
\hline & \multirow{5}{*}{ S690QH } & SHS $50 \times 50 \times 5$ & 797 & 838 & 22.4 \\
\hline & & SHS $100 \times 100 \times 5.6$ & 821 & 829 & 20.1 \\
\hline & & SHS $90 \times 90 \times 5.6$ & 789 & 825 & 16.6 \\
\hline & & RHS $100 \times 50 \times 6.3$ & 792 & 834 & 20.9 \\
\hline & & RHS $100 \times 50 \times 5.6$ & 778 & 822 & 19.7 \\
\hline \multirow{9}{*}{ 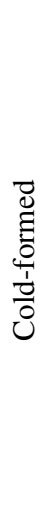 } & \multirow{3}{*}{$\mathrm{S} 500 \mathrm{MC}$} & SHS $130 \times 130 \times 4$ & 573 & 649 & 24.8 \\
\hline & & SHS $200 \times 200 \times 4$ & 568 & 650 & 26.3 \\
\hline & & SHS $200 \times 200 \times 5$ & 567 & 648 & 23.5 \\
\hline & \multirow{2}{*}{ S700MC } & SHS $110 \times 110 \times 4$ & 758 & 816 & 21.0 \\
\hline & & SHS $150 \times 150 \times 4$ & 799 & 874 & 21.4 \\
\hline & \multirow{4}{*}{ S960QC } & SHS $100 \times 100 \times 4$ & 1005 & 1098 & 9.8 \\
\hline & & SHS $120 \times 120 \times 4$ & 1049 & 1207 & 9.8 \\
\hline & & SHS $150 \times 150 \times 7$ & 1114 & 1199 & 7.8 \\
\hline & & SHS $120 \times 120 \times 3$ & 1044 & 1169 & 8.8 \\
\hline
\end{tabular}


Table 3: Average of measured flat face material properties from tensile coupon tests for each of the tested section sizes

\begin{tabular}{|c|c|c|c|c|c|c|c|c|}
\hline \multicolumn{2}{|c|}{ Steel grade } & Cross-section & $\begin{array}{l}\mathrm{f}_{\mathrm{y}} \\
\left(\mathrm{N} / \mathrm{mm}^{2}\right)\end{array}$ & $\begin{array}{l}\mathrm{f}_{\mathrm{u}} \\
\left(\mathrm{N} / \mathrm{mm}^{2}\right)\end{array}$ & $\begin{array}{l}\varepsilon_{\mathrm{u}} \\
(\%)\end{array}$ & $\begin{array}{l}\varepsilon_{\mathrm{f}} \\
(\%)\end{array}$ & $\begin{array}{l}Z \\
(\%)\end{array}$ & $\mathrm{f}_{\mathrm{u}} / \mathrm{f}_{\mathrm{y}}$ \\
\hline \multirow{11}{*}{ 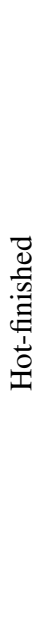 } & \multirow{6}{*}{ S460NH } & SHS $50 \times 50 \times 5$ & 505 & 620 & 14.9 & 31.0 & 67.1 & 1.23 \\
\hline & & SHS $50 \times 50 \times 4$ & 523 & 623 & 15.9 & 28.5 & 65.0 & 1.19 \\
\hline & & SHS $100 \times 100 \times 5$ & 511 & 616 & 14.9 & 29.2 & 64.9 & 1.21 \\
\hline & & SHS $90 \times 90 \times 3.6$ & 500 & 655 & 14.7 & 27.9 & 62.3 & 1.31 \\
\hline & & RHS $100 \times 50 \times 6.3$ & 498 & 699 & 13.3 & 26.3 & 59.5 & 1.40 \\
\hline & & RHS $100 \times 50 \times 4.5$ & 498 & 645 & 13.9 & 28.3 & 64.0 & 1.30 \\
\hline & \multirow{5}{*}{ S690QH } & SHS $50 \times 50 \times 5$ & 759 & 790 & 7.5 & 21.7 & 56.7 & 1.04 \\
\hline & & SHS $100 \times 100 \times 5.6$ & 782 & 798 & 7.0 & 20.3 & 56.3 & 1.02 \\
\hline & & SHS $90 \times 90 \times 5.6$ & 774 & 790 & 7.4 & 20.1 & 61.9 & 1.02 \\
\hline & & RHS $100 \times 50 \times 6.3$ & 799 & 820 & 7.1 & 19.4 & 57.6 & 1.03 \\
\hline & & RHS $100 \times 50 \times 5.6$ & 777 & 811 & 7.4 & 19.3 & 55.0 & 1.04 \\
\hline \multirow{9}{*}{$\begin{array}{l}\frac{D}{0} \\
\text { : } \\
\frac{0}{0} \\
\frac{0}{0}\end{array}$} & \multirow{3}{*}{ S500MC } & SHS $130 \times 130 \times 4$ & 582 & 652 & 10.1 & 29.6 & 59.9 & 1.12 \\
\hline & & SHS $200 \times 200 \times 4$ & 531 & 599 & 11.1 & 30.9 & 63.3 & 1.13 \\
\hline & & SHS $200 \times 200 \times 5$ & 535 & 609 & 11.0 & 21.6 & 71.6 & 1.17 \\
\hline & \multirow{2}{*}{ S700MC } & SHS $110 \times 110 \times 4$ & 732 & 794 & 11.7 & 25.7 & 58.5 & 1.09 \\
\hline & & SHS $150 \times 150 \times 4$ & 800 & 857 & 5.5 & 21.6 & 58.2 & 1.08 \\
\hline & \multirow{4}{*}{ S960QC } & SHS $100 \times 100 \times 4$ & 981 & 1096 & 1.3 & 9.4 & - & 1.12 \\
\hline & & SHS $120 \times 120 \times 4$ & 1051 & 1207 & 1.7 & 9.8 & - & 1.15 \\
\hline & & SHS $120 \times 120 \times 3$ & 1050 & 1168 & 1.6 & 8.8 & - & 1.11 \\
\hline & & SHS $150 \times 150 \times 7$ & 1106 & 1179 & 0.7 & 7.8 & - & 1.08 \\
\hline
\end{tabular}


Table 4: Average of measured corner region material properties from tensile coupon tests for each of the tested section sizes

\begin{tabular}{|c|c|c|c|c|c|c|c|c|}
\hline \multicolumn{2}{|c|}{ Steel grade } & Cross-section & $\begin{array}{l}\mathrm{f}_{\mathrm{yc}} \\
\left(\mathrm{N} / \mathrm{mm}^{2}\right)\end{array}$ & $\begin{array}{l}\mathrm{f}_{\mathrm{uc}} \\
\left(\mathrm{N} / \mathrm{mm}^{2}\right)\end{array}$ & $\begin{array}{l}\varepsilon_{\mathrm{uc}} \\
(\%)\end{array}$ & $\begin{array}{l}\varepsilon_{\mathrm{fc}} \\
(\%)\end{array}$ & $\begin{array}{l}\mathrm{Z}_{\mathrm{c}} \\
(\%)\end{array}$ & $\mathrm{f}_{\mathrm{uc}} / \mathrm{f}_{\mathrm{yc}}$ \\
\hline \multirow{11}{*}{ 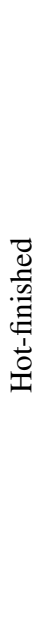 } & \multirow{6}{*}{ S460NH } & SHS $50 \times 50 \times 5$ & 481 & 631 & 12.7 & $26.2^{*}$ & 83.2 & 1.31 \\
\hline & & SHS $50 \times 50 \times 4$ & 477 & 627 & 12.0 & 23.5 & 80.0 & 1.32 \\
\hline & & SHS $100 \times 100 \times 5$ & 528 & 636 & 5.8 & 23.3 & 77.3 & 1.20 \\
\hline & & SHS $90 \times 90 \times 3.6$ & 487 & 614 & 6.1 & $18.8^{*}$ & 78.3 & 1.26 \\
\hline & & RHS $100 \times 50 \times 6.3$ & 505 & 700 & 17.4 & 26.4 & 67.6 & 1.39 \\
\hline & & RHS $100 \times 50 \times 4.5$ & 512 & 646 & 9.4 & 22.0 & 71.6 & 1.26 \\
\hline & \multirow{5}{*}{ S690QH } & SHS $50 \times 50 \times 5$ & 782 & 813 & 6.9 & 18.2 & 78.0 & 1.04 \\
\hline & & SHS $100 \times 100 \times 5.6$ & 774 & 792 & 5.1 & 20.2 & 76.7 & 1.02 \\
\hline & & SHS $90 \times 90 \times 5.6$ & 754 & 784 & 9.0 & $18.3^{*}$ & 70.6 & 1.04 \\
\hline & & RHS $100 \times 50 \times 6.3$ & 768 & 806 & 4.5 & $22.0^{*}$ & 75.0 & 1.05 \\
\hline & & RHS $100 \times 50 \times 5.6$ & 771 & 781 & 4.9 & 19.2 & 75.9 & 1.01 \\
\hline \multirow{9}{*}{$\begin{array}{l}\frac{D}{0} \\
\stackrel{0}{0} \\
\frac{1}{0} \\
ن\end{array}$} & \multirow{3}{*}{ S500MC } & SHS $130 \times 130 \times 4$ & 614 & 739 & 1.7 & 9.4 & 45.0 & 1.09 \\
\hline & & SHS $200 \times 200 \times 4$ & 597 & 740 & 1.9 & 10.9 & 52.7 & 1.22 \\
\hline & & SHS $200 \times 200 \times 5$ & 616 & 741 & 2.3 & 12.2 & 57.3 & 1.10 \\
\hline & \multirow{2}{*}{ S700MC } & SHS $110 \times 110 \times 4$ & 786 & 920 & 1.8 & 8.0 & 44.6 & 1.10 \\
\hline & & SHS $150 \times 150 \times 4$ & 891 & 1091 & 2.1 & 7.6 & 31.1 & 1.11 \\
\hline & \multirow{4}{*}{ S960QC } & SHS $100 \times 100 \times 4$ & 990 & 1156 & 1.5 & - & - & 1.17 \\
\hline & & SHS $120 \times 120 \times 4$ & 1234 & 1412 & 1.5 & - & - & 1.14 \\
\hline & & SHS $120 \times 120 \times 3$ & 1094 & 1246 & 1.6 & - & - & 1.13 \\
\hline & & SHS $150 \times 150 \times 7$ & 1211 & 1389 & 1.2 & - & - & 1.14 \\
\hline
\end{tabular}

* Coupon failed in the tensile machine jaws. 
Table 5: Comparison between the flat and corner coupon test results

\begin{tabular}{|c|c|c|c|c|c|c|c|c|}
\hline \multicolumn{2}{|c|}{ Steel grade } & Cross-section & $\mathrm{f}_{\mathrm{yc}} / \mathrm{f}_{\mathrm{y}}$ & $\mathrm{f}_{\mathrm{uc}} / \mathrm{f}_{\mathrm{u}}$ & $\varepsilon_{\mathrm{uc}} / \varepsilon_{\mathrm{u}}$ & $\varepsilon_{\mathrm{fc}} / \varepsilon_{\mathrm{f}}$ & $\mathrm{Z}_{\mathrm{c}} / \mathrm{Z}$ & $\frac{f_{u c}}{f_{f_{c}}} / \frac{f_{u}}{f_{y}}$ \\
\hline \multirow{13}{*}{ 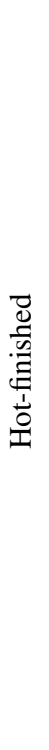 } & \multirow{7}{*}{ S460NH } & SHS $50 \times 50 \times 5$ & 0.95 & 1.02 & 0.85 & 0.87 & 1.24 & 1.07 \\
\hline & & SHS $50 \times 50 \times 4$ & 0.91 & 1.01 & 0.76 & 0.86 & 1.23 & 1.10 \\
\hline & & SHS $100 \times 100 \times 5$ & 1.03 & 1.03 & 0.39 & 0.84 & 1.19 & 1.00 \\
\hline & & SHS $90 \times 90 \times 3.6$ & 0.97 & 0.94 & 0.41 & 0.69 & 1.26 & 0.96 \\
\hline & & RHS $100 \times 50 \times 6.3$ & 1.01 & 1.00 & 1.31 & 1.05 & 1.14 & 0.99 \\
\hline & & RHS $100 \times 50 \times 4.5$ & 1.03 & 1.00 & 0.68 & 0.82 & 1.12 & 0.97 \\
\hline & & Mean & 0.99 & 1.00 & 0.73 & 0.86 & 1.20 & 1.02 \\
\hline & \multirow{6}{*}{ S690QH } & SHS $50 \times 50 \times 5$ & 1.03 & 1.03 & 0.92 & 1.01 & 1.37 & 1.00 \\
\hline & & SHS $100 \times 100 \times 5.6$ & 0.99 & 0.99 & 0.73 & 1.10 & 1.36 & 1.00 \\
\hline & & SHS $90 \times 90 \times 5.6$ & 0.97 & 0.99 & 1.22 & 0.92 & 1.14 & 1.02 \\
\hline & & RHS $100 \times 50 \times 6.3$ & 0.96 & 0.98 & 0.63 & 1.32 & 1.31 & 1.02 \\
\hline & & RHS $100 \times 50 \times 5.6$ & 0.99 & 0.96 & 0.67 & 1.03 & 1.38 & 0.97 \\
\hline & & Mean & 0.99 & 0.99 & 0.78 & 1.07 & 1.31 & 1.00 \\
\hline \multirow{12}{*}{$\begin{array}{l}\frac{D}{\mathscr{d}} \\
\frac{0}{0} \\
\frac{1}{0} \\
\frac{0}{0}\end{array}$} & \multirow{4}{*}{ S500MC } & SHS $130 \times 130 \times 4$ & 1.05 & 1.13 & 0.17 & 0.32 & 0.75 & 1.08 \\
\hline & & SHS $200 \times 200 \times 4$ & 1.12 & 1.23 & 0.17 & 0.35 & 0.83 & 1.10 \\
\hline & & SHS $200 \times 200 \times 5$ & 1.15 & 1.52 & 0.21 & 0.57 & 0.74 & 1.08 \\
\hline & & Mean & 1.11 & 1.29 & 0.18 & 0.41 & 0.77 & 1.09 \\
\hline & \multirow{3}{*}{ S700MC } & SHS $110 \times 110 \times 4$ & 1.08 & 1.16 & 0.15 & 0.35 & 0.76 & 1.07 \\
\hline & & SHS $150 \times 150 \times 4$ & 1.11 & 1.27 & 0.39 & 0.57 & 0.53 & 1.15 \\
\hline & & Mean & 1.10 & 1.22 & 0.27 & 0.46 & 0.65 & 1.11 \\
\hline & \multirow{5}{*}{ S960QC } & SHS $100 \times 100 \times 4$ & 1.01 & 1.05 & 1.12 & - & - & 1.05 \\
\hline & & SHS $120 \times 120 \times 4$ & 1.17 & 1.17 & 0.86 & - & - & 1.00 \\
\hline & & SHS $120 \times 120 \times 3$ & 1.04 & 1.07 & 1.00 & - & - & 0.97 \\
\hline & & SHS $150 \times 150 \times 7$ & 1.09 & 1.16 & 1.69 & - & - & 0.94 \\
\hline & & Mean & 1.08 & 1.11 & 1.17 & - & - & 0.99 \\
\hline
\end{tabular}


Table 6: Measured dimensions of full cross-section tensile test specimens

\begin{tabular}{|c|c|c|c|c|c|c|c|}
\hline \multicolumn{2}{|c|}{ Steel grade } & Specimen & & & & & \\
\hline \multirow{11}{*}{ 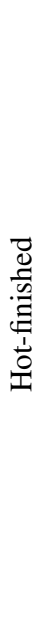 } & \multirow{6}{*}{ S460NH } & SHS $50 \times 50 \times 5$ & 548.3 & 50.2 & 50.4 & 5.02 & 3.52 \\
\hline & & SHS $50 \times 50 \times 4$ & 547.9 & 50.6 & 51.3 & 3.82 & 3.38 \\
\hline & & SHS $100 \times 100 \times 5$ & 548.7 & 99.2 & 99.6 & 5.27 & 5.00 \\
\hline & & SHS $90 \times 90 \times 3.6$ & 548.1 & 99.2 & 89.9 & 3.77 & 5.00 \\
\hline & & RHS $100 \times 50 \times 6.3$ & 548.1 & 100.0 & 50.0 & 6.41 & 4.88 \\
\hline & & RHS $100 \times 50 \times 4.5$ & 547.6 & 100.1 & 50.7 & 4.71 & 5.00 \\
\hline & \multirow{5}{*}{ S690QH } & SHS $50 \times 50 \times 5$ & 548.7 & 50.8 & 50.6 & 4.89 & 3.25 \\
\hline & & SHS $100 \times 100 \times 5.6$ & 548.2 & 100.4 & 100.5 & 5.74 & 4.88 \\
\hline & & SHS $90 \times 90 \times 5.6$ & 548.3 & 90.5 & 91.4 & 5.76 & 4.50 \\
\hline & & RHS $100 \times 100 \times 6.3$ & 548.0 & 100.3 & 50.5 & 6.44 & 5.00 \\
\hline & & RHS $100 \times 50 \times 5.6$ & 548.9 & 100.5 & 50.0 & 5.72 & 5.13 \\
\hline
\end{tabular}

Table 7: Key results of full cross-section tensile tests

\begin{tabular}{|c|c|c|c|c|c|c|c|}
\hline \multicolumn{2}{|c|}{ Steel grade } & Specimen & $\begin{array}{l}\mathrm{f}_{\mathrm{y}, \mathrm{cs}} \\
\left(\mathrm{N} / \mathrm{mm}^{2}\right)\end{array}$ & $\begin{array}{l}\mathrm{f}_{\mathrm{u}, \mathrm{cs}} \\
\left(\mathrm{N} / \mathrm{mm}^{2}\right)\end{array}$ & $\begin{array}{l}\varepsilon_{\mathrm{u}, \mathrm{cs}} \\
(\%)\end{array}$ & $\begin{array}{l}\varepsilon_{\mathrm{f}, \mathrm{Cs}} \\
(\%)\end{array}$ & $\mathrm{f}_{\mathrm{u}, \mathrm{cs}} / \mathrm{f}_{\mathrm{y}, \mathrm{cs}}$ \\
\hline \multirow{11}{*}{ 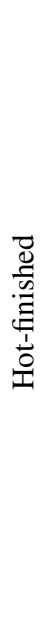 } & \multirow{6}{*}{$\mathrm{S} 460 \mathrm{NH}$} & SHS $50 \times 50 \times 5$ & 502 & 644 & 11.1 & 13.9 & 1.28 \\
\hline & & SHS $50 \times 50 \times 4$ & 535 & 665 & 10.6 & 14.0 & 1.24 \\
\hline & & SHS $100 \times 100 \times 5$ & 529 & 716 & 12.5 & 14.2 & 1.35 \\
\hline & & SHS $90 \times 90 \times 3.6$ & 479 & 684 & 10.8 & 13.1 & 1.43 \\
\hline & & RHS $100 \times 50 \times 6.3$ & 512 & 747 & 10.3 & 13.4 & 1.46 \\
\hline & & RHS $100 \times 50 \times 4.5$ & 474 & 679 & 11.5 & 13.0 & 1.43 \\
\hline & \multirow{5}{*}{ S690QH } & SHS $50 \times 50 \times 5$ & 813 & 838 & 5.6 & 9.4 & 1.03 \\
\hline & & SHS $100 \times 100 \times 5.6$ & - & 764 & 0.3 & 0.3 & - \\
\hline & & SHS $90 \times 90 \times 5.6$ & 828 & 847 & 3.2 & 3.2 & 1.02 \\
\hline & & RHS $100 \times 50 \times 6.3$ & 805 & 850 & 6.2 & 7.4 & 1.06 \\
\hline & & RHS $100 \times 50 \times 5.6$ & 779 & 823 & 5.6 & 7.2 & 1.06 \\
\hline
\end{tabular}


Table 8: Measured local geometric imperfections

\begin{tabular}{|c|c|c|c|c|c|c|}
\hline \multicolumn{2}{|c|}{ Steel grade } & Cross-section & $\bar{\lambda}_{\mathrm{p}}$ & $\omega_{0}(\mathrm{~mm})$ & $\omega_{\mathrm{EN}}(\mathrm{mm})$ & $\omega_{0} / \omega_{\mathrm{EN}}$ \\
\hline \multirow{11}{*}{ 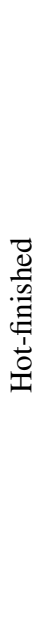 } & \multirow{6}{*}{ S460NH } & SHS $50 \times 50 \times 5$ & 0.17 & 0.05 & 0.50 & 0.11 \\
\hline & & SHS $50 \times 50 \times 4$ & 0.25 & 0.04 & 0.50 & 0.09 \\
\hline & & SHS $100 \times 100 \times 5$ & 0.39 & 0.08 & 1.00 & 0.08 \\
\hline & & SHS $90 \times 90 \times 3.6$ & 0.50 & 0.08 & 0.90 & 0.09 \\
\hline & & RHS $100 \times 50 \times 6.3$ & 0.31 & 0.05 & 1.00 & 0.05 \\
\hline & & RHS $100 \times 50 \times 4.5$ & 0.44 & 0.07 & 1.00 & 0.07 \\
\hline & \multirow{5}{*}{ S690QH } & SHS $50 \times 50 \times 5$ & 0.22 & 0.08 & 0.50 & 0.15 \\
\hline & & SHS $100 \times 100 \times 5.6$ & 0.44 & 0.08 & 1.01 & 0.08 \\
\hline & & SHS $90 \times 90 \times 5.6$ & 0.39 & 0.09 & 0.91 & 0.10 \\
\hline & & RHS $100 \times 50 \times 6.3$ & 0.39 & 0.11 & 1.00 & 0.11 \\
\hline & & RHS $100 \times 50 \times 5.6$ & 0.44 & 0.16 & 1.01 & 0.16 \\
\hline \multirow{9}{*}{ 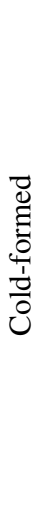 } & \multirow{3}{*}{$\mathrm{S} 500 \mathrm{MC}$} & SHS $130 \times 130 \times 4$ & 0.77 & 0.95 & 1.04 & 0.91 \\
\hline & & SHS $200 \times 200 \times 4$ & 1.20 & 0.56 & 1.62 & 0.35 \\
\hline & & SHS $200 \times 200 \times 5$ & 0.93 & 0.47 & 1.59 & 0.29 \\
\hline & \multirow{2}{*}{ S700MC } & SHS $110 \times 110 \times 4$ & 0.79 & 0.60 & 0.88 & 0.69 \\
\hline & & SHS $150 \times 150 \times 4$ & 1.12 & 1.22 & 1.21 & 1.01 \\
\hline & \multirow{4}{*}{ S960QC } & SHS $100 \times 100 \times 4$ & 0.64 & 0.91 & 0.80 & 1.15 \\
\hline & & SHS $120 \times 120 \times 4$ & 0.93 & 0.54 & 0.97 & 0.55 \\
\hline & & SHS $120 \times 120 \times 3$ & 1.30 & 0.23 & 0.96 & 0.24 \\
\hline & & SHS $150 \times 150 \times 7$ & 0.66 & 0.46 & 1.22 & 0.37 \\
\hline
\end{tabular}


Table 9: Measured dimensions of the stub column test specimens

\begin{tabular}{|c|c|c|c|c|c|c|c|}
\hline \multicolumn{2}{|c|}{ Steel grade } & \multirow{2}{*}{$\begin{array}{l}\text { Specimen } \\
\text { SHS } 50 \times 50 \times 5\end{array}$} & \multirow{2}{*}{$\begin{array}{l}\mathrm{L} \\
(\mathrm{mm}) \\
150.0\end{array}$} & \multirow{2}{*}{$\begin{array}{l}\mathrm{h} \\
\frac{(\mathrm{mm})}{50.3}\end{array}$} & \multirow{2}{*}{$\begin{array}{l}\mathrm{b} \\
(\mathrm{mm}) \\
50.4\end{array}$} & \multirow{2}{*}{$\begin{array}{l}\mathrm{t} \\
(\mathrm{mm}) \\
5.02\end{array}$} & \multirow{2}{*}{$\begin{array}{l}\mathrm{r}_{\mathrm{i}} \\
(\mathrm{mm}) \\
3.50\end{array}$} \\
\hline \multirow{11}{*}{ 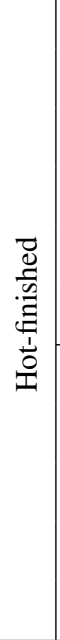 } & \multirow{6}{*}{ S460NH } & & & & & & \\
\hline & & SHS $50 \times 50 \times 4$ & 150.0 & 50.3 & 50.3 & 3.82 & 3.38 \\
\hline & & SHS $100 \times 100 \times 5$ & 300.1 & 99.8 & 99.4 & 5.27 & 5.00 \\
\hline & & SHS $90 \times 90 \times 3.6$ & 269.8 & 90.4 & 90.8 & 3.77 & 5.00 \\
\hline & & RHS $100 \times 50 \times 6.3$ & 300.0 & 99.9 & 49.8 & 6.41 & 4.88 \\
\hline & & RHS $100 \times 50 \times 4.5$ & 300.0 & 99.7 & 49.8 & 4.71 & 5.00 \\
\hline & \multirow{5}{*}{ S690QH } & SHS $50 \times 50 \times 5$ & 149.9 & 50.4 & 50.3 & 4.89 & 3.25 \\
\hline & & SHS $100 \times 100 \times 5.6$ & 300.1 & 100.7 & 100.4 & 5.74 & 4.88 \\
\hline & & SHS $90 \times 90 \times 5.6$ & 270.0 & 91.0 & 90.6 & 5.76 & 4.50 \\
\hline & & RHS $100 \times 50 \times 6.3$ & 300.0 & 100.2 & 50.1 & 6.44 & 5.00 \\
\hline & & RHS $100 \times 50 \times 5.6$ & 300.1 & 100.5 & 49.8 & 5.72 & 5.13 \\
\hline \multirow{18}{*}{ 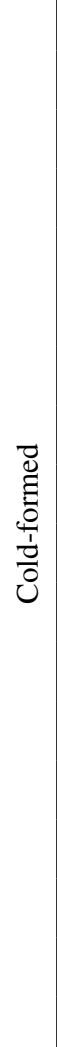 } & \multirow{6}{*}{ S500MC } & SHS $130 \times 130 \times 4-1$ & 445.0 & 130.5 & 131.0 & 4.16 & 3.83 \\
\hline & & SHS $130 \times 130 \times 4-2$ & 445.0 & 130.0 & 132.5 & 4.24 & 3.83 \\
\hline & & SHS $200 \times 200 \times 5-1$ & 653.0 & 199.0 & 202.0 & 5.14 & 5.50 \\
\hline & & SHS $200 \times 200 \times 5-2$ & 655.0 & 200.0 & 201.0 & 5.19 & 5.50 \\
\hline & & SHS $200 \times 200 \times 4-1$ & 655.0 & 202.0 & 202.5 & 4.13 & 3.83 \\
\hline & & SHS $200 \times 200 \times 4-2$ & 650.0 & 200.0 & 202.0 & 4.32 & 3.83 \\
\hline & \multirow{4}{*}{ S700MC } & SHS $110 \times 110 \times 4-1$ & 385.0 & 110.0 & 110.5 & 3.82 & 3.00 \\
\hline & & SHS $110 \times 110 \times 4-2$ & 385.0 & 109.5 & 110.0 & 3.83 & 3.00 \\
\hline & & SHS $150 \times 150 \times 4-1$ & 505.0 & 151.5 & 153.0 & 3.95 & 4.17 \\
\hline & & SHS $150 \times 150 \times 4-2$ & 505.0 & 151.5 & 153.0 & 3.94 & 4.17 \\
\hline & \multirow{8}{*}{ S960QC } & SHS $100 \times 100 \times 4-1$ & 350.0 & 99.5 & 101.0 & 4.04 & 10.00 \\
\hline & & SHS $100 \times 100 \times 4-2$ & 350.0 & 100.0 & 101.0 & 4.04 & 10.00 \\
\hline & & SHS $120 \times 120 \times 4-1$ & 410.0 & 121.5 & 122.5 & 3.96 & 8.62 \\
\hline & & SHS $120 \times 120 \times 4-2$ & 410.0 & 123.0 & 122.5 & 3.96 & 8.75 \\
\hline & & SHS $120 \times 120 \times 3-1$ & 411.0 & 120.0 & 121.0 & 3.07 & 3.69 \\
\hline & & SHS $120 \times 120 \times 3-2$ & 412.0 & 120.0 & 121.0 & 3.09 & 3.56 \\
\hline & & SHS $150 \times 150 \times 7-2$ & 499.0 & 153.0 & 154.0 & 6.92 & 10.75 \\
\hline & & SHS $150 \times 150 \times 7-4$ & 500.0 & 154.0 & 152.5 & 6.92 & 11.50 \\
\hline
\end{tabular}


Table 10: Summary of stub column test results

\begin{tabular}{|c|c|c|c|c|c|}
\hline \multicolumn{2}{|c|}{ Steel grade } & \multirow{2}{*}{$\begin{array}{l}\text { Specimen } \\
\text { SHS } 50 \times 50 \times 5\end{array}$} & \multirow{2}{*}{$\begin{array}{l}\mathrm{N}_{\mathrm{u}} \\
(\mathrm{kN}) \\
645\end{array}$} & \multirow{2}{*}{$\begin{array}{l}\delta_{\mathrm{u}} \\
(\mathrm{mm}) \\
14.57\end{array}$} & Failure mode \\
\hline \multirow{11}{*}{ 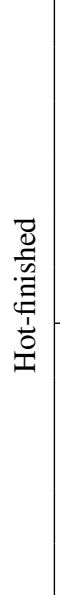 } & \multirow{6}{*}{ S460NH } & & & & Elephant foot buckling \\
\hline & & SHS $50 \times 50 \times 4$ & 478 & 9.07 & Elephant foot buckling \\
\hline & & SHS $100 \times 100 \times 5$ & 1042 & 6.92 & Local buckling \\
\hline & & SHS $90 \times 90 \times 3.6$ & 628 & 0.93 & Local buckling \\
\hline & & RHS $100 \times 50 \times 6.3$ & 1188 & 12.54 & Local + global buckling \\
\hline & & RHS $100 \times 50 \times 4.5$ & 713 & 6.28 & Local buckling \\
\hline & \multirow{5}{*}{ S690QH } & SHS $50 \times 50 \times 5$ & 804 & 8.92 & Elephant foot buckling \\
\hline & & SHS $100 \times 100 \times 5.6$ & 1671 & 5.40 & Local buckling \\
\hline & & SHS $90 \times 90 \times 5.6$ & 1512 & 6.08 & Local buckling \\
\hline & & RHS $100 \times 50 \times 6.3$ & 1410 & 6.58 & Local + global buckling \\
\hline & & RHS $100 \times 50 \times 5.6$ & 1244 & 4.53 & Local + global buckling \\
\hline \multirow{18}{*}{$\begin{array}{l}\overrightarrow{0} \\
\stackrel{0}{0} \\
\frac{0}{0} \\
\frac{1}{0} \\
0 \\
ن\end{array}$} & \multirow{6}{*}{ S500MC } & SHS $130 \times 130 \times 4-1$ & 1214 & 2.56 & Local buckling \\
\hline & & SHS $130 \times 130 \times 4-2$ & 1173 & 2.35 & Local buckling \\
\hline & & SHS $200 \times 200 \times 5-1$ & 1689 & 2.05 & Local buckling \\
\hline & & SHS $200 \times 200 \times 5-2$ & 1693 & 2.08 & Local buckling \\
\hline & & SHS $200 \times 200 \times 4-1$ & 1097 & 1.94 & Local buckling \\
\hline & & SHS $200 \times 200 \times 4-2$ & 1109 & 2.29 & Local buckling \\
\hline & \multirow{4}{*}{ S700MC } & SHS $110 \times 110 \times 4-1$ & 1099 & - & Local buckling \\
\hline & & SHS $110 \times 110 \times 4-2$ & 1011 & 1.43 & Local buckling \\
\hline & & SHS $150 \times 150 \times 4-1$ & 1113 & 2.35 & Local buckling \\
\hline & & SHS $150 \times 150 \times 4-2$ & 1120 & 2.26 & Local buckling \\
\hline & \multirow{8}{*}{ S960QC } & SHS $100 \times 100 \times 4-1$ & 1443 & 2.84 & Local buckling \\
\hline & & SHS $100 \times 100 \times 4-2$ & 1427 & 2.44 & Local buckling \\
\hline & & SHS $120 \times 120 \times 4-1$ & 1372 & 2.13 & Local buckling \\
\hline & & SHS $120 \times 120 \times 4-2$ & 1360 & 2.16 & Local buckling \\
\hline & & SHS $120 \times 120 \times 3-1$ & 837 & 2.30 & Local buckling \\
\hline & & SHS $120 \times 120 \times 3-2$ & 832 & 2.61 & Local buckling \\
\hline & & SHS $150 \times 150 \times 7-1$ & 4396 & 5.22 & Local buckling \\
\hline & & SHS $150 \times 150 \times 7-2$ & 4430 & 5.17 & Local buckling \\
\hline
\end{tabular}


Table 11: Comparison of results from full cross-section tensile tests and tensile flat coupon tests

\begin{tabular}{|c|c|c|c|c|c|c|c|}
\hline \multicolumn{2}{|c|}{ Steel grade } & Specimen & $\mathrm{f}_{\mathrm{y}, \mathrm{cs}} / \mathrm{f}_{\mathrm{y}}$ & $\mathrm{f}_{\mathrm{u}, \mathrm{cs}} / \mathrm{f}_{\mathrm{u}}$ & $\varepsilon_{\mathrm{u}, \mathrm{cs}} / \varepsilon_{\mathrm{u}}$ & $\varepsilon_{\mathrm{f}, \mathrm{cs}} / \varepsilon_{\mathrm{f}}$ & $\frac{f_{u, c s}}{f_{y, c s}} / \frac{f_{u}}{f_{y}}$ \\
\hline \multirow{11}{*}{ 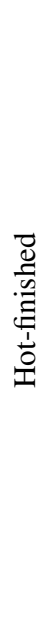 } & \multirow{6}{*}{ S460NH } & SHS $50 \times 50 \times 5$ & 1.00 & 1.04 & 0.84 & 0.45 & 1.04 \\
\hline & & SHS $50 \times 50 \times 4$ & 1.02 & 1.07 & 0.76 & 0.49 & 1.04 \\
\hline & & SHS $100 \times 100 \times 5$ & 1.03 & 1.16 & 0.86 & 0.49 & 1.12 \\
\hline & & SHS $90 \times 90 \times 3.6$ & 0.96 & 1.04 & 0.76 & 0.47 & 1.09 \\
\hline & & RHS $100 \times 50 \times 6.3$ & 1.03 & 1.07 & 0.81 & 0.51 & 1.04 \\
\hline & & RHS $100 \times 50 \times 4.5$ & 0.95 & 1.05 & 0.85 & 0.46 & 1.11 \\
\hline & \multirow{5}{*}{ S690QH } & SHS $50 \times 50 \times 5$ & 1.07 & 1.06 & 0.83 & 0.43 & 0.99 \\
\hline & & SHS $100 \times 100 \times 5.6$ & - & 0.96 & - & - & - \\
\hline & & SHS $90 \times 90 \times 5.6$ & 1.07 & 1.07 & 0.44 & 0.16 & 1.00 \\
\hline & & RHS $100 \times 100 \times 6.3$ & 1.01 & 1.04 & 0.98 & 0.39 & 1.03 \\
\hline & & RHS $100 \times 50 \times 5.6$ & 1.00 & 1.02 & 0.83 & 0.38 & 1.01 \\
\hline
\end{tabular}

Table 12: Summary of reliability analysis results for Class 3 slenderness limit

\begin{tabular}{lcccccc}
\hline Class 3 limit & $\mathrm{n}$ & $\mathrm{k}_{\mathrm{d}, \mathrm{n}}$ & $\mathrm{b}$ & $\mathrm{V}_{\delta}$ & $\mathrm{V}_{\mathrm{r}}$ & $\gamma_{\mathrm{M} 0}$ \\
\hline EN 1993-1-1 (c/t $\varepsilon=42)$ & 46 & 3.317 & 0.998 & 0.083 & 0.101 & 1.30 \\
Proposed $(\mathrm{c} / \mathrm{t} \varepsilon=38)$ & 44 & 3.328 & 0.988 & 0.083 & 0.102 & 1.26 \\
\hline
\end{tabular}

